\title{
Model studies of volatile diesel exhaust particle formation: are organic vapours involved in nucleation and growth?
}

\author{
L. Pirjola ${ }^{1,2}$, M. Karl ${ }^{3}$, T. Rönkköo ${ }^{4}$, and F. Arnold ${ }^{5,6}$ \\ ${ }^{1}$ Department of Technology, Metropolia University of Applied Sciences, P.O. Box 4021, 00180 Helsinki, Finland \\ ${ }^{2}$ Department of Physics, University of Helsinki, P.O. Box 64, 00014 Helsinki, Finland \\ ${ }^{3}$ Norwegian Institute for Air Research, P.O. Box 100, 2027 Kjeller, Norway \\ ${ }^{4}$ Aerosol Physics Laboratory, Department of Physics, Tampere University of Technology, P.O. Box 692, \\ 33101 Tampere, Finland \\ ${ }^{5}$ Max-Planck-Institut für Kernphysik, Heidelberg, Germany \\ ${ }^{6}$ Deutsches Zentrum für Luft and Raumfahrt (DLR), Obenpfaffenhofen, Germany
}

Correspondence to: L. Pirjola (liisa.pirjola@metropolia.fi, liisa.pirjola@ helsinki.fi)

Received: 2 November 2014 - Published in Atmos. Chem. Phys. Discuss.: 17 February 2015

Revised: 14 August 2015 - Accepted: 7 September 2015 - Published: 23 September 2015

\begin{abstract}
A high concentration of volatile nucleation mode particles (NUP) formed in the atmosphere when the exhaust cools and dilutes has hazardous health effects and it impairs the visibility in urban areas. Nucleation mechanisms in diesel exhaust are only poorly understood. We performed model studies using two sectional aerosol dynamics process models AEROFOR and MAFOR on the formation of particles in the exhaust of a diesel engine, equipped with an oxidative after-treatment system and running with low fuel sulfur content (FSC) fuel, under laboratory sampling conditions where the dilution system mimics real-world conditions. Different nucleation mechanisms were tested. Based on the measured gaseous sulfuric acid (GSA) and non-volatile core and soot particle number concentrations of the raw exhaust, the model simulations showed that the best agreement between model predictions and measurements in terms of particle number size distribution was obtained by barrier-free heteromolecular homogeneous nucleation between the GSA and a semivolatile organic vapour combined with the homogeneous nucleation of GSA alone. Major growth of the particles was predicted to occur due to the similar organic vapour at concentrations of $(1-2) \times 10^{12} \mathrm{~cm}^{-3}$. The pre-existing core and soot mode concentrations had an opposite trend on the NUP formation, and the maximum NUP formation was predicted if a diesel particle filter (DPF) was used. On the other hand, the
\end{abstract}

model predicted that the NUP formation ceased if the GSA concentration in the raw exhaust was less than $10^{10} \mathrm{~cm}^{-3}$, which was the case when biofuel was used.

\section{Introduction}

Regardless of many improvements in vehicle technology exhaust particles emitted from traffic constitute major air pollutants in urban environments (e.g. Pey et al., 2009). Although the mass emissions of diesel particles have been reduced due to the tightened emission regulations, the number emission of exhaust nanoparticles has been reported to be significant (Rönkkö et al., 2013; Lähde et al., 2010). These nonregulated particles can penetrate deepest into the human pulmonary and blood-vascular systems having hazardous health effects (Pope III and Dockery, 2006; Sioutas et al., 2005; Kettunen et al., 2007; Su et al., 2008; Alföldy et al., 2009). Exhaust particles also affect the climate by scattering or absorbing solar radiation and participating in cloud formation (Charlson et al., 1992; Bond et al., 2013).

The major source of diesel particulate mass is soot particles in the size range of $50-1000 \mathrm{~nm}$ by mass, but in the size range of $40-100 \mathrm{~nm}$ by number (mobility diameter) (Kittelson, 1998). These particles are formed in the combustion pro- 
cess and are composed of non-volatile carbonaceous soot agglomerates, onto which semi-volatile vapours can condense (e.g. Kittelson, 1998; Tobias et al., 2001). The Euro VI level diesel vehicles are equipped with diesel particle filters (DPF) or partial diesel particle filters (pDPF) (Heikkilä et al., 2009) which remove totally or partly soot particles. The oxidative after-treatment systems such as diesel oxidising catalyst (DOC) reduce exhaust hydrocarbon concentrations but simultaneously increase $\mathrm{SO}_{2}$ to $\mathrm{SO}_{3}$ conversion enhancing gaseous sulfuric acid (GSA) formation (Arnold et al., 2006, 2012; Maricq et al., 2002). The GSA has a very low saturation vapour pressure, and it has been shown to participate in condensation and nucleation processes during the dilution and cooling of the exhaust (Arnold et al., 2006, 2012; Rönkkö et al., 2013; Shi and Harrison, 1999; Tobias et al., 2001; Schneider et al., 2005; Khalek et al., 2003). These nucleation mode particles (called hereafter volatile nucleation mode) consist of volatile material such as water, sulfate and hydrocarbons (Kittelson, 1998) which evaporates when heated at $265^{\circ} \mathrm{C}$. With some vehicle technologies and in some driving conditions, nanoparticles possessing a nonvolatile core of around $10 \mathrm{~nm}$ or less in size have been observed (hereafter called core mode). These particles are suggested to be formed by fuel aliphatic hydrocarbons (Filippo et al., 2008) or lubricant oil metal compounds (Kittelson et al., 2008; Rönkkö et al., 2013; Karjalainen et al., 2014) coated by condensing volatile hydrocarbon and sulfur compounds (Rönkkö et al., 2007, 2013).

Although the measurements indicate that sulfuric acid participates in the production of volatile exhaust particles, the nucleation mechanism is not known. Numerous different nucleation theories involving sulfuric acid such as binary homogeneous nucleation (BHN) (Kulmala et al., 1998; Vehkamäki et al., 2002, 2003), ternary nucleation (Napari el al., 2002; Merikanto et al., 2007), activation nucleation (Kulmala et al., 2006), kinetic nucleation (Weber et al., 1997), ion-induced nucleation (Raes and Janssens, 1985; Arnold et al., 1999; Yu and Turco, 2000), and recently sulfuric acid-amine nucleation (Almeida et al., 2013) as well as sulfuric acid along with oxidized organic vapours (e.g. Riccobono et al., 2014) have been proposed to explain nucleation bursts under atmospheric conditions. Since vehicle exhaust includes similar species as in the atmosphere, the NUP formation might occur in the same way. Arnold et al. (1999) have actually made mass spectrometric measurements of chemical ions present in the exhaust of combustion engines, including car engines and aircraft gas turbine engines. On the other hand, Ma et al. (2008) reported that ion-induced nucleation did not play an important role in the NUP formation of diesel exhaust. Ion-induced nucleation is not considered in this study.

Recently published models simulating the formation and growth of exhaust particles can be divided into two groups. Some of them are process models (Shi and Harrison, 1999; Voutsis et al., 2005; Lemmetty et al., 2008; Du and Yu, 2006, 2008) as is also the model considered in this study, whereas some are computational fluid dynamics (CFD) models coupled with aerosol dynamics (Uhrner et al., 2007; Albriet et al., 2010; Liu et al., 2011) and with the major turbulent mixing processes as well (Wang and Zhang, 2012).

Shi and Harrison (1999) concluded that the BHN predicted nucleation rates several orders of magnitude lower than those measured, even though the fuel sulfur content (FSC) was as high as $300-500 \mathrm{ppm}$, and no sink processes such as condensation and coagulation were taken into account. The simulation results reported by Vouitsis et al. (2005) showed that the barrier-free nucleation scheme, where clusters are always stable against evaporation (Clement and Ford, 1999), could predict the NUP concentration rather well for low sulfur fuel ( $\mathrm{FSC}=10 \mathrm{ppm})$, whereas the nucleation rate proportional to the square of sulfuric acid saturation vapour pressure was more appropriate for high sulfur fuel $(\mathrm{FSC}=250 \mathrm{ppm})$. Lemmetty et al. (2008) discovered that by assuming the high $\mathrm{SO}_{2}$ to $\mathrm{SO}_{3}$ conversion ratio of $90 \%$ BHN nucleation reproduced the measured size distributions opposed to barrier-free nucleation. Du and Yu (2006) concluded that by using their kinetic BHN model for the vehicles running on the fuel with the FSC of $330 \mathrm{ppm}$, the BHN scheme could not predict the measured NUP concentrations if the $\mathrm{SO}_{2}$ to $\mathrm{SO}_{3}$ conversion ratio was $1 \%$, but that it was appropriate for the ratios greater than $4 \%$ even though FSC was less than $50 \mathrm{ppm}$. If the FSC was $15 \mathrm{ppm}$, the BHN was the main source of NUP only for vehicles equipped with continuously regenerating particle filters (Du and Yu, 2008).

All of these studies indicate that low or semi-volatile condensable vapours other than GSA are required to explain the measured particle number size distributions. However, all of the previous model studies suffer from the lack of GSA measurements. It is well-known that even a small change in the GSA concentration can cause a several-orders-of-magnitude difference in the binary nucleation rate.

Based on the model simulations, the main objective of this study is to quantify the relevant nucleation mechanism and the concentrations of semi-volatile $\left(\mathrm{COV}_{\mathrm{s}}\right)$ and/or lowvolatile $\left(\mathrm{COV}_{1}\right)$ condensable organic vapours needed to explain the diesel particle evolution in an ageing chamber under laboratory conditions which mimic well the atmospheric dilution conditions. For the first time the applicability of nucleation between an organic compound and sulfuric acid in diesel exhaust was investigated. The other objective is to investigate how changes in vehicle after-treatment technologies, fuel and lubricant oil affect exhaust particle nucleation and growth.

The model simulations were performed by an aerosol dynamics model AEROFOR (e.g. Pirjola, 1999; Pirjola and Kulmala, 2001; Lemmetty et al., 2008; Arnold et al., 2012). The GSA and particle concentrations in the raw exhaust were adopted from the measurements by Arnold et al. (2012) and Rönkkö et al. (2013). The first model simulations by AEROFOR for the same engine equipped with the DOC and DPF have already been described in Arnold et al. (2012). Since 
AEROFOR produces only the time evolution of the particle number size distributions and concentrations, some of the simulations were repeated with another aerosol dynamics model MAFOR (Karl et al., 2011) which is able to produce the mass and composition size distributions of a multicomponent aerosol.

Both models, AEROFOR and MAFOR, are Lagrangian type box models which are well established and evaluated. Although these models are not able to give a spatial distribution of temperature and aerosol scalars in the sampling system (Olin et al., 2015), they were able to achieve the goals of this study, and subsequently increase our understanding on the formation and transformation mechanisms in diesel exhaust under laboratory and atmospheric conditions.

\section{Methods}

\subsection{Sampling system and measurements}

Since the detailed description of the measurements and instrumentation can be found in Arnold et al. (2012) and Rönkkö et al. (2013), only a short description relevant to modelling is given here. The emission measurements of a Euro IV standard heavy duty diesel engine were performed on an engine dynamometer. Four steady-state conditions with engine loads of 100, 75, 50 and $25 \%$ were studied. The FSC was $36 \mathrm{ppm}$, additionally the FSC of $6 \mathrm{ppm}$ and biofuel ( $\mathrm{FSC}<1 \mathrm{ppm}$ ) were used in some experiments. Different after-treatment systems were used, however, this research mainly deals with the cases when the engine was equipped with DOC and pDPF.

The particle sampling and dilution system was a modified version of partial flow sampling system (Ntzhiachristos et al., 2004). The system consisted of a porous tube type primary diluter followed by an ageing chamber and an ejector type diluter (Fig. 1). Although it is clear that the system simplifies the real-world vehicle exhaust dilution process and thus does not completely reproduce all the details of the realworld process, it has been shown to reproduce the real-world exhaust nucleation particle formation and growth relatively well (Gieschaskiel et al., 2005; Rönkkö et al., 2006; Keskinen and Rönkkö, 2010). Therefore, the system has been used especially in laboratory studies focusing on vehicle exhaust nanoparticles (e.g. Vaaraslahti et al., 2005; Rönkkö et al., 2006, 2013; Arnold et al., 2012).

The ageing chamber was used to ensure adequate residence time for the condensational growth of the nucleation mode particles in the cooled and diluted aerosol sample. The following ejector diluter was used to bring the sample into the ambient pressures and to ensure that the particle number concentration was in the measurement range of particle measurement equipment, without significant effects on particles formed during exhaust dilution and cooling (Giechaskiel et al., 2009). In the primary diluter, the dilution air tempera- ture was $30^{\circ} \mathrm{C}$, the relative humidity was close to zero and the dilution ratio was adjusted to 12 . The dilution ratios were calculated from the measured $\mathrm{CO}_{2}$ concentrations of the diluted exhaust sample and the raw exhaust. Based on the constant exhaust flow rate in the dilution and sampling system $\left(55 \mathrm{~L} \mathrm{~min}^{-1}\right)$ and the measurements mentioned in Fig. 1, the residence time of the exhaust in the tube between the PD and $\mathrm{AC}$ was $0.1 \mathrm{~s}$ and in the ageing chamber $2.6 \mathrm{~s}$. Furthermore, exhaust temperature was measured at two points marked in Fig. 1 .

Particle number size distributions of the exhaust were measured using two scanning mobility particle sizers (SMPS) measuring the particle diameters 3-60 and 10$430 \mathrm{~nm}$. Also the size distributions for all engine loads were measured using a thermodenuder (TD) in which the volatile material was evaporated at $265^{\circ} \mathrm{C}$ temperature. The size distributions were corrected for particle losses in both SMPS and thermodenuder (Heikkilä et al., 2009) (Table 1).

The gaseous sulfuric acid GSA (Table 1) was monitored by a CIMS (chemical ion mass spectrometer) whose setup consists of a flow tube reactor through which the exhaust plume is passed. Details of the instrument can be found in Fiedler et al. (2005) and Arnold et al. (2012). In addition, the acidic trace gases were measured in a way analogous to GSA. The uncertainty of the measured GSA present in the flow tube reactor was $\pm 30 \%$, whereas only a lower limit concentration was obtained for all other acidic gases, several of which could be identified as dicarboxylic acids, including malonic, succinic, glutaric and adipic acids (Arnold et al., 2012).

\subsection{Model descriptions}

The model simulations were performed by a slightly updated version of an atmospheric chemistry and aerosol dynamics box model AEROFOR (e.g. Pirjola, 1999; Pirjola and Kulmala, 2001; Pirjola et al., 2004; Arnold et al., 2012). The model includes gas-phase chemistry, formation of thermodynamically stable clusters by different nucleation mechanisms, condensation of $\mathrm{H}_{2} \mathrm{SO}_{4}, \mathrm{H}_{2} \mathrm{O}$ and an organic vapour onto particles (Fuchs and Sutugin, 1970) taking into account molecular dimensions (Lehtinen and Kulmala, 2003), Brownian coagulation of particles (Fuchs, 1964), temperature and cooling profiles (Lemmetty et al., 2006), wall losses (Voutsis et al., 2005) as well as mixing with the particle-free dry diluted air. The Kelvin effect was taken into account in the condensation processes of organic vapour and sulfuric acid. The saturation vapour pressure of sulfuric acid was calculated according to Eq. (8) in Vehkamäki et al. (2003), and surface tension as explained in Vehkamäki et al. (2003), valid at least up to $360-400 \mathrm{~K}$.

In this study, four nucleation mechanisms were used: (1) classical binary homogeneous $\mathrm{H}_{2} \mathrm{SO}_{4}-\mathrm{H}_{2} \mathrm{O}$ nucleation (BHN) (Vehkamäki et al., 2003); (2) activation theory (ACT) (Kulmala et al., 2006), where under the steady state nucleation rate the number of activated clusters is linearly pro- 


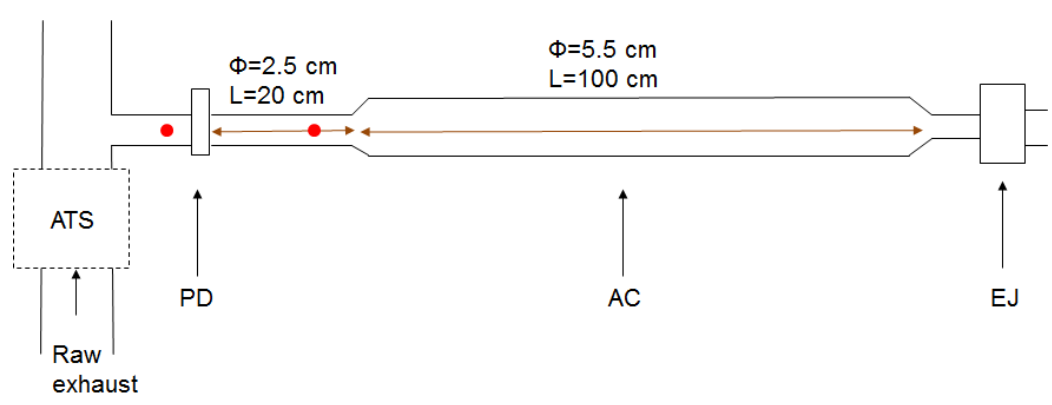

Figure 1. Schematic figure of diluting and ageing exhaust. ATS $=$ after-treatment system, PD $=$ porous diluter $(12: 1)$, AC $=$ ageing chamber with the volume of $2.4 \mathrm{dm}^{3}$, EJ = ejector diluter $(8: 1)$. Red circles refer to temperature measurements. Exhaust flow rate through the dilution/sampling system was kept constant $55 \mathrm{~L} \mathrm{~min}^{-1}$.

portional to the sulfuric acid concentration, i.e. the nucleation rate $J=A\left[\mathrm{H}_{2} \mathrm{SO}_{4}\right]$ ( $A=$ activation coefficient); (3) kinetic nucleation (KIN) (McMurry and Friedlander, 1979; Weber et al., 1997; Sihto et al., 2006), where homogeneous homomolecular nucleation occurs involving two sulfuric acid molecules, and thus the nucleation rate $J$ is proportional to the square of the sulfuric acid, i.e. $J=K\left[\mathrm{H}_{2} \mathrm{SO}_{4}\right]^{2}$ ( $K=$ kinetic coefficient which includes the collision frequence and the probability of formation of a stable particle after the collision); (4) homogeneous homomolecular nucleation of sulfuric acid along with homogeneous heteromolecular nucleation between sulfuric acid and organic vapour molecules (HET) (Paasonen et al., 2010), i.e. $J=$ $K_{1}\left[\mathrm{H}_{2} \mathrm{SO}_{4}\right]^{2}+K_{2}\left[\mathrm{H}_{2} \mathrm{SO}_{4}\right][\mathrm{org}]$. The diameter of the nucleated particle was assumed to be $1.5 \mathrm{~nm}$ (Kulmala et al., 2007).

The condensable organic vapours that contribute to particle evolution in diesel exhaust are not yet identified. However, based on the measurements, Arnold et al. (2012), Kawamura and Kaplan (1987), and Zervas et al. (2001) have observed condensable dicarboxylic acids in the exhaust of vehicles. On the other hand, the TDMA (two tandem differential mobility analyzers) volatility measurements by Sakurai et al. (2003) indicate that the organic component of diesel nanoparticles was comprised of compounds with carbon numbers in the $\mathrm{C}_{24}-\mathrm{C}_{32}$ range, which were derived almost entirely from unburned oil. Although there may be thousands of different low and semi-volatile condensable organic vapours we have used in AEROFOR a semi-volatile organic compound called $\mathrm{COV}_{\mathrm{s}}$ with the properties of adipic acid to represent all condensable organic vapours. Moreover, a low-volatile organic compound with volatility corresponding to that of $n$-alkane $\mathrm{C}_{34} \mathrm{H}_{70}$ (constituent of the engine oil) called $\mathrm{COV}_{1}$ was used in MAFOR.

In addition to condensation, $\mathrm{COV}_{\mathrm{S}}$ was assumed to participate in heteromolecular nucleation. The thermodynamical properties for $\mathrm{COV}_{\mathrm{s}}$ were adopted from literature, i.e. temperature-dependent expressions for the saturation vapour pressure from Bilde et al. (2003) and for the surface tension by Riipinen et al. (2007) (Table 2). The molecular weight of
$0.146 \mathrm{~kg} \mathrm{~mol}^{-1}$ and the liquid phase density of $1085 \mathrm{~kg} \mathrm{~m}^{-3}$ were used. The vapour concentration is a free parameter. Pure adipic acid is insoluble in water. Hämeri et al. (2002) have measured that the organic fraction of the mixtures containing adipic acid and ammonium sulfate does not contribute to water uptake. However, Yeung et al. (2009) found out that adipic acid can have effects similar to those of more water-soluble organic species. AEROFOR assumes that $\mathrm{COV}_{\mathrm{s}}$ takes up water as sulfuric acid, and therefore the water content and wet diameters of the particles might be overestimated.

To minimise the effect of numerical diffusion typical for sectional models, 100 size sections turned out to be sufficient. The fixed sectional presentation for aerosol size distribution was used since the sectional representation is more advantageous for the treatment of simultaneous nucleation and particle transformation than the modal aerosol representation. Especially in diesel exhaust, the rapid formation of volatile particles may lead to size distribution peaks that do not have a lognormal shape.

The set of stiff differential equations describing the time evolution of particle number concentrations in each section as well as the vapour concentrations was solved using $\mathrm{Nu}-$ merical Algorithms Group Ltd library FORTRAN-routine D02EJF (1990). The time step was set to $0.01 \mathrm{~s}$.

Some of the cases simulated by AEROFOR were repeated by a Multicomponent Aerosol Dynamic model MAFOR (Karl et al., 2011). The model describes aerosol formation by different nucleation processes (details on nucleation options in Karl et al., 2012a), here only the HET nucleation option was used. Further aerosol processes are condensation of $\mathrm{H}_{2} \mathrm{SO}_{4}, \mathrm{H}_{2} \mathrm{O}, \mathrm{COV}_{\mathrm{s}}$ and an extremely low-volatile nonhygroscopic vapour $\mathrm{COV}_{1}$ (Table 2), as well as Brownian coagulation, and mixing with the particle-free dry diluted air. $\mathrm{COV}_{\mathrm{S}}$ has the properties of adipic acid (same as in AEROFOR) but different water uptake since the hygroscopic properties of $\mathrm{COV}_{\mathrm{s}}$ in MAFOR were that of sodium succinate (Peng and Chan, 2001), i.e. $\mathrm{COV}_{\mathrm{s}}$ starts to take up water at $\mathrm{RH}>48 \%$, and has a growth factor of 1.85 from 10 to $90 \%$ $\mathrm{RH}$. The saturation vapour pressure for $\mathrm{COV}_{1}$ was adopted from Lemmon and Goodwill (2000). Due to its extremely 
Table 1. Lognormal parameters (number concentration $N$, geometric mean diameter $D_{\mathrm{g}}$, standard deviation $\sigma$ ) for non-volatile exhaust particles and GSA concentration in raw exhaust at different engine loads and exhaust temperatures. Index 1 refers to the core mode and index 2 to the soot mode.

\begin{tabular}{rrrrrrrrr}
\hline $\begin{array}{r}\text { Engine load } \\
(\%)\end{array}$ & $\begin{array}{r}T \\
(\mathrm{~K})\end{array}$ & $\begin{array}{r}\text { GSA } \\
\left(\mathrm{cm}^{-3}\right) \times 10^{10}\end{array}$ & $\begin{array}{r}N_{1} \\
\left(\mathrm{~cm}^{-3}\right) \times 10^{6}\end{array}$ & $\begin{array}{r}D_{\mathrm{g} 1} \\
(\mathrm{~nm})\end{array}$ & $\sigma_{1}$ & $\begin{array}{c}N_{2} \\
\left(\mathrm{~cm}^{-3}\right) \times 10^{6}\end{array}$ & $\begin{array}{c}D_{\mathrm{g} 2} \\
(\mathrm{~nm})\end{array}$ & $\sigma_{2}$ \\
\hline 100 & 697 & 0.28 & 1.66 & 8.8 & 1.25 & 1.96 & 49 & 2.15 \\
100 & 697 & 0.34 & 1.66 & 8.8 & 1.25 & 1.96 & 49 & 2.15 \\
100 & 697 & 1.36 & 1.66 & 8.8 & 1.25 & 1.96 & 49 & 2.15 \\
100 & 697 & 4.17 & 1.66 & 8.8 & 1.25 & 1.96 & 49 & 2.15 \\
100 & 697 & 9.75 & 1.66 & 8.8 & 1.25 & 1.96 & 49 & 2.15 \\
100 & 697 & 15.3 & 1.66 & 8.8 & 1.25 & 1.96 & 49 & 2.15 \\
100 & 697 & 26.6 & 1.66 & 8.8 & 1.25 & 1.96 & 49 & 2.15 \\
100 & 697 & 44.0 & 1.66 & 8.8 & 1.25 & 1.96 & 49 & 2.15 \\
100 & 697 & 201 & 1.66 & 8.8 & 1.25 & 1.96 & 49 & 2.15 \\
75 & 657 & 11.5 & 1.53 & 8.4 & 1.26 & 1.79 & 49 & 1.98 \\
75 & 657 & 25.0 & 1.53 & 8.4 & 1.26 & 1.79 & 49 & 1.98 \\
75 & 657 & 30.2 & 1.53 & 8.4 & 1.26 & 1.79 & 49 & 1.98 \\
50 & 618 & 11.1 & 0.427 & 7.5 & 1.23 & 5.34 & 56 & 1.87 \\
\hline
\end{tabular}

Table 2. Physical properties of the condensable vapours. $\mathrm{COV}_{\mathrm{s}}$ was used in AEROFOR, whereas $\mathrm{COV}_{\mathrm{S}}$ and $\mathrm{COV}_{1}$ were used in $\mathrm{MAFOR}$.

\begin{tabular}{llllll}
\hline & $\begin{array}{l}p^{0}(298 \mathrm{~K}) \\
(\mathrm{Pa})\end{array}$ & $\begin{array}{l}\text { molar weight } \\
\left(\mathrm{g} \mathrm{mol}^{-1}\right)\end{array}$ & $\begin{array}{l}\text { surface tension } \\
(298 \mathrm{~K})\left(\mathrm{N} \mathrm{m}^{-1}\right)\end{array}$ & hygroscopic & nucleation \\
\hline $\mathrm{COV}_{\mathrm{s}}$ & $1.63 \times 10^{-5 \mathrm{a}}$ & 146 & $0.34^{\mathrm{b}}$ & yes & yes \\
$\mathrm{COV}_{1}$ & $5.0 \times 10^{-11 \mathrm{c}}$ & 478 & $\mathrm{~d}^{\mathrm{d}}$ & no & no \\
\hline
\end{tabular}

${ }^{\text {a }}$ Bilde et al. (2003), ${ }^{b}$ Riipinen et al. (2007), ${ }^{c}$ Lemmon and Goodwill (2000). ${ }^{\mathrm{d}}$ Kelvin effect not considered (due to

low vapour pressure)

low vapour pressure, the Kelvin effect was not included in the $\mathrm{COV}_{1}$ condensation. Thus $\mathrm{COV}_{1}$ assists in the initial growth of nucleated particles of 1-2 nm diameter in size for which the Kelvin barrier is huge. The Kelvin effect drops sharply as the particle size increases due to its exponential dependence on diameter, enabling condensation of more volatile compounds, such as $\mathrm{COV}_{\mathrm{s}}$. Since $n$-alkanes do not form hydrogen bonds with sulfuric acid, it is further assumed that $\mathrm{COV}_{1}$ is not a nucleating compound.

The mass transfer of gas molecules to particles is calculated using the Analytical Predictor of Condensation scheme (Jacobson, 1997). The composition of particles in any size bin can change with time due to multicomponent condensation and/or due to coagulation of particles. Thus, the sizesegregated chemical composition of the generated particulate matter can be tracked at high temporal resolution. MAFOR has been evaluated with chamber data (Karl et al., 2012b), particle number measurements at a motorway (Keuken et al., 2012), and it has been shown to compare well with AEROFOR (see Karl et al., 2011). In this study, 120 size bins were used to represent the aerosol size distribution ranging from $1.5 \mathrm{~nm}$ to $10 \mu \mathrm{m}$ diameter. An effective density of $1200 \mathrm{~kg} \mathrm{~m}^{-3}$ (Virtanen et al., 2002) was used for soot parti- cles. The tests with 1000 and $1500 \mathrm{~kg} \mathrm{~m}^{-3}$ showed that the results were not sensitive to the applied density value.

\subsection{Input values based on the measurements}

In the model simulations with AEROFOR and MAFOR the raw exhaust dilutes rapidly by dry air $(T=303 \mathrm{~K})$ so that the final dilution ratio $D_{\mathrm{f}}$ is 12 . Since it is very difficult to mathematically analyse the dilution and cooling processes they are described in simple parameters as in Lemmetty et al. (2006). A detailed simulation of cluster and particle formation during cooling in a porous diluter is out of the scope of this study (see e.g. Pyykönen et al., 2007; Olin et al., 2015). According to Lemmetty et al. (2006), the temperature was assumed to follow the exponential curve of the Newtonian cooling

$T(t)=T_{\text {fin }}+\left(T_{1}-T_{\text {fin }}\right) \exp \left(-\frac{t}{\tau_{\mathrm{c}}}\right)$,

where $T_{1}$ is the raw exhaust temperature and $T_{\text {fin }}$ the final exhaust temperature. The parameter $\tau_{\mathrm{c}}$ is the time constant for cooling, and it refers to the time when the remaining excess temperature is $\sim 37 \%(=1 / e \%)$ of the original value. In this study, $\tau_{\mathrm{c}}$ was determined based on the temperature measurements at two points shown in Fig. 1, and a value of $0.03 \mathrm{~s}$ 


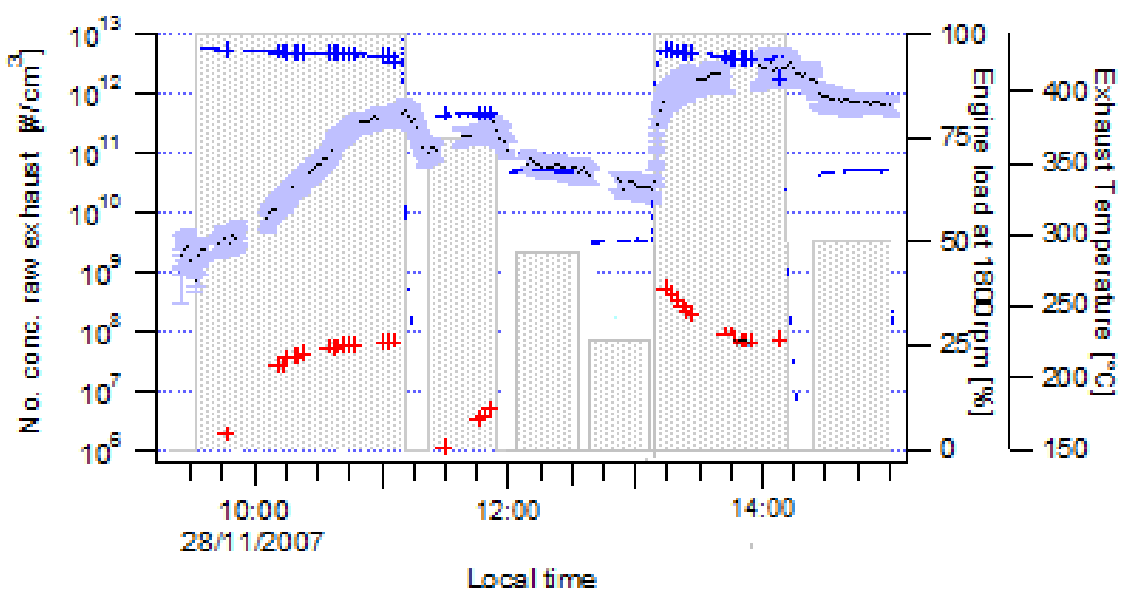

Figure 2. Time series of the concentrations of GSA (black curve) along with standard deviations (light blue shaded area), and particles larger than $3 \mathrm{~nm}$ (red crosses) in the raw exhaust as a function of engine load (dotted grey bars) at $1800 \mathrm{rpm}$. Also shown is the exhaust temperature (blue crosses).

was obtained at all engine loads. Similarly to Lemmetty et al. (2006), dilution is modelled by using an exponential equation

$\mathrm{DR}(t)=\mathrm{DR}_{\mathrm{f}}^{1 / \tau_{\mathrm{d}}}, t<\tau_{\mathrm{d}}$.

The dilution time constant $\tau_{\mathrm{d}}$ is the time in which the system has achieved the final dilution ratio, and no dilution occurs after this. In this study, $\tau_{\mathrm{d}}$ is a free parameter. Its value was assumed to be $0.12 \mathrm{~s}$; however, sensitivity tests will be presented in Sect. 3.3.1. It should be noted that by assuming that cooling is caused only by dilution, the upper limit for $\tau_{\mathrm{c}}$ is determined by an equation (Lemmetty et al., 2006)

$\tau_{\mathrm{c}} \leq \frac{\tau_{\mathrm{d}}}{\ln \left(\mathrm{DR}_{\mathrm{f}}\right)}$.

Consequently, $\tau_{\mathrm{d}}$ must be $\geq 0.075 \mathrm{~s}$.

The initial exhaust particle size distribution (raw exhaust) accounted for two modes, the soot mode and the core mode, both formed in the combustion processes in the engine. The modal geometric mean diameters $\left(D_{\mathrm{g}}\right)$, number concentrations and standard deviations (Table 1 ) were adopted from the measurements (Rönkkö et al., 2013).

The initial raw-exhaust GSA concentrations were as well adopted from the measurements (Arnold et al., 2012; Rönkkö et al., 2013). During the $100 \%$ engine load periods the GSA concentration varied from $2.2 \times 10^{9}$ to $3 \times 10^{12} \mathrm{~cm}^{-3}$, during the $75 \%$ engine load period from $1.2 \times 10^{11}$ to $3 \times 10^{11} \mathrm{~cm}^{-3}$, and during the $50 \%$ period it was around $6 \times 10^{10}-1 \times$ $10^{11} \mathrm{~cm}^{-3}$ (Fig. 2). The history of the after-treatment system (ATS) had a large effect on the concentrations, especially, during the first $100 \%$ engine load the increasing trend in the GSA concentration indicates strong storage effect of sulfuric acid onto the walls of the ATS.

Model simulations were performed mainly at the $100 \%$ engine load phases even though some simulations were re- peated at 75 and $50 \%$ engine loads. The models were initiated by the measured GSA and non-volatile particle concentrations given in Table 1 .

\section{Results and discussion}

\subsection{Comparison of the nucleation mechanisms}

\subsubsection{Binary homogeneous nucleation}

In the first set of model simulations the BHN mechanism was assumed. Figure $3 \mathrm{a}$ illustrates the evolution of the particle number concentration $\mathrm{N}_{3}$, gas concentrations and nucleation rate, along with the particle number size distribution at the end of the simulation when the initial GSA concentration was $2 \times 10^{12} \mathrm{~cm}^{-3}$, which was the measured stabilized concentration at the end of the second $100 \%$ engine load in Fig. 2 . Also shown is the measured particle size distribution at the end of the ageing chamber (Fig. 3b black curve), and time development of the condensation sink CS (Fig. 3c).

Two features emerge from the figures. First, nucleation occurs very fast, and it starts after $0.1 \mathrm{~s}$ just at the entrance of the ageing chamber, and reaches the momentary maximum value $3.0 \times 10^{9} \mathrm{~cm}^{-3} \mathrm{~s}^{-1}$ after $0.23 \mathrm{~s}$. Nucleation is totally suppressed after one second if no condensable organic vapour is present, and somewhat faster, after $0.6 \mathrm{~s}$, if the condensable organic vapour concentration is present with a concentration of $8 \times 10^{12} \mathrm{~cm}^{-3}$. Sulfuric acid concentration decreases first mainly by dilution, but after the $0.12 \mathrm{~s}$ nucleation and condensation are competing processes. The time evolution of the condensation sink (CS) (e.g. Pirjola et al., 1999; Kulmala et al., 2001), whose inverse is a measure of the lifetime of condensable vapour molecules in the exhaust, is presented in Fig. 3c for the simulations with and without 
a)

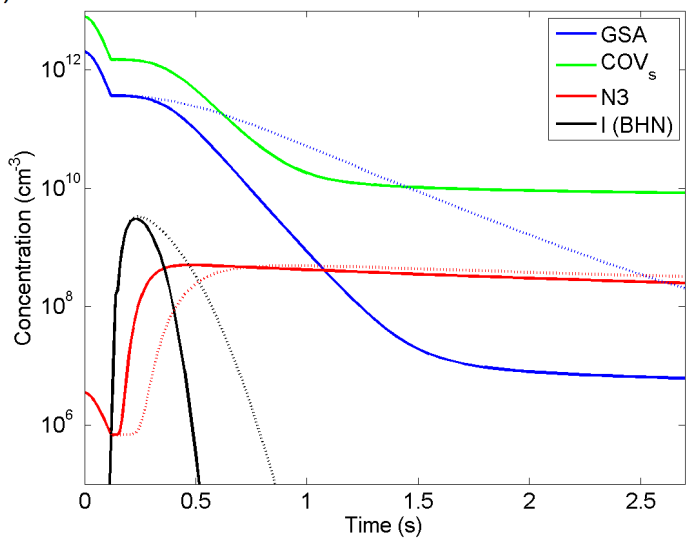

b)

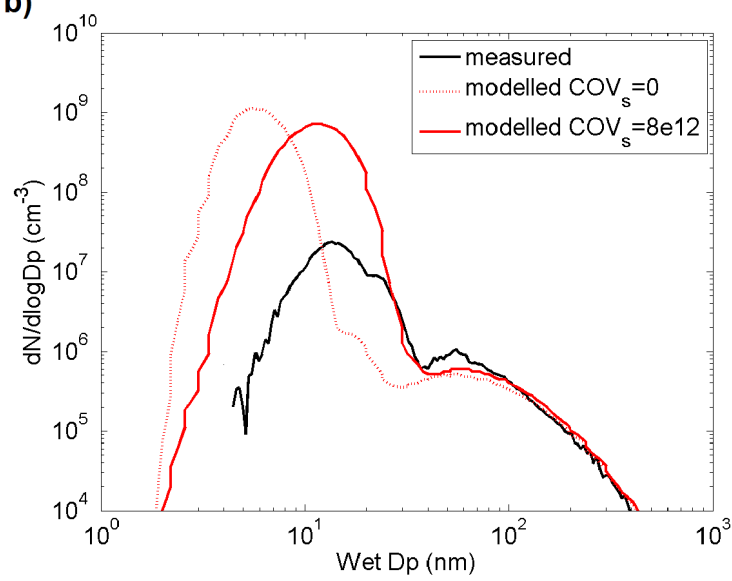

c)

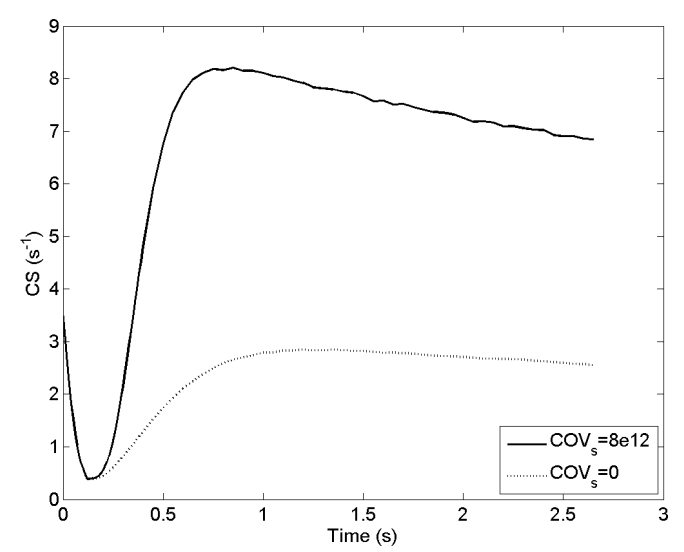

Figure 3. (a) Time evolution of particle number concentration $\left(\mathrm{N}_{3}\right)$, gaseous sulfuric acid (GSA) and condensable organic vapour $\left(\mathrm{COV}_{\mathrm{s}}\right)$ in $\mathrm{cm}^{-3}$, as well as nucleation rate $(I)$ in $\mathrm{cm}^{-3} \mathrm{~s}^{-1}$ by the BHN mechanism. Solid lines refer to $\mathrm{COV}_{\mathrm{s}}=8 \times 10^{12} \mathrm{~cm}^{-3}$ and dashed lines to $\mathrm{COV} s=0$. (b) Measured (black) and modelled (red) particle number size distribution at the end of the ageing chamber. (c) Condensation sink for sulfuric acid. Initial $\mathrm{GSA}=2 \times 10^{12} \mathrm{~cm}^{-3}, \mathrm{COV}_{\mathrm{s}}=8 \times 10^{12} \mathrm{~cm}^{-3}$ and $\mathrm{COV}_{\mathrm{s}}=0$.

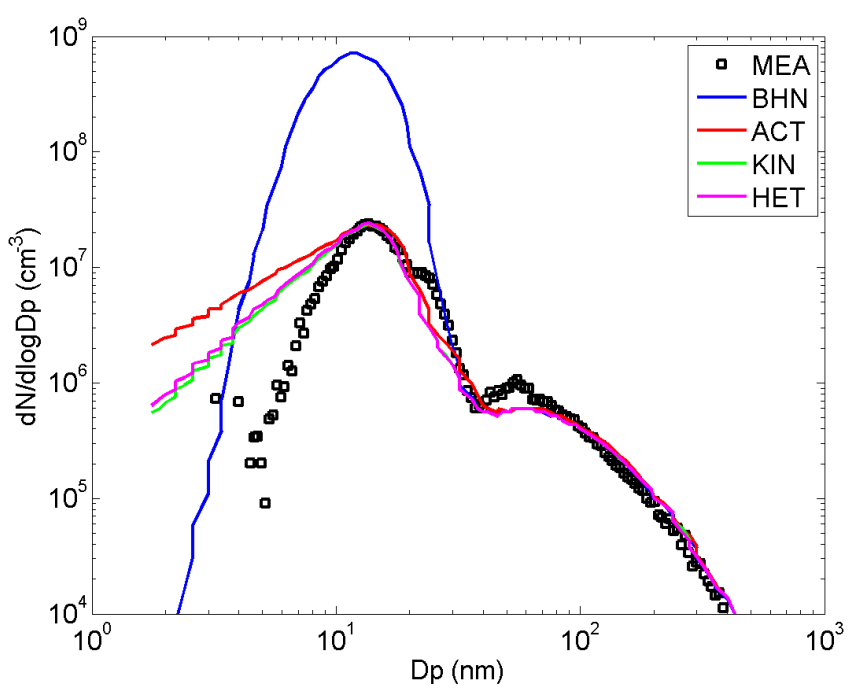

Figure 4. Comparison of measured and modelled particle size distributions, considering different nucleation mechanisms. Engine load was $100 \%$, initial GSA $=2.0 \times 10^{12} \mathrm{~cm}^{-3}, \mathrm{COV}_{\mathrm{s}}=$ $6 \times 10^{11} \mathrm{~cm}^{-3}$, except for BHN it was $8 \times 10^{12} \mathrm{~cm}^{-3}$. The simulation time was $2.7 \mathrm{~s}$. Black squares refer to the measured size distribution by the SMPS after the ageing chamber.

organic vapour. The initial CS is $3.5 \mathrm{~s}^{-1}$ based on the dry core and soot modes. Due to dilution it decreases during the first $0.17 \mathrm{~s}$ but then steeply increases up to a value of $8 \mathrm{~s}^{-1}$ over the duration of the nucleation, and after the suppression of nucleation slightly decreases as the number concentration decreases due to coagulation, even though condensation still grows the particles. For comparison, typical atmospheric CS values are in the range of $10^{-4}-10^{-1} \mathrm{~s}^{-1}$. It should be noted that in this study the dilution ratio was only 12 , whereas in atmospheric conditions it might be even more than 1000 at plume ages of $2.7 \mathrm{~s}$ (Kittelson et al., 1998; Du and Yu, 2008). Typically, the nucleation mode has been fully formed at the dilution ratio of approximately 100 (Keskinen and Rönkkö, 2010) or after less than $0.7 \mathrm{~s}$ residence time in the atmosphere (Rönkkö et al., 2007). The predicted GSA concentrations at the end of the ageing chamber are $1.2 \times 10^{8} \mathrm{~cm}^{-3}$ and $6 \times 10^{6} \mathrm{~cm}^{-3}$ without and with the condensable organic vapour, respectively. Unfortunately, these values cannot be compared with observations since only the raw-exhaust GSA concentration was measured.

Secondly, the newly formed particles are not able to grow to the measured sizes by sulfuric acid. At the end of the simulation, the modelled geometric mean diameter of the nucleation mode is only $5.5 \mathrm{~nm}$. To reach the measured modal mean value of $13.7 \mathrm{~nm}$ the $\mathrm{COV}_{\mathrm{s}}$ concentration should be as high as $8 \times 10^{12} \mathrm{~cm}^{-3}$. Consequently, the concentration of particles smaller than $40 \mathrm{~nm}$ covering the grown volatile and non-volatile nucleation mode particles is much higher than the observed one (Fig. 3b); the modelled total particle 
Table 3. Shown here are the initial condensable organic vapour concentrations $\left(\mathrm{COV}_{\mathrm{S}}\right)$ and activation coefficient $(A)$ as well as the initial $\mathrm{COV}_{\mathrm{s}}$ and kinetic coefficient $(K)$ as a function of the initial gaseous sulfuric acid concentration (GSA). Also shown is the predicted and measured number concentration of particles larger than $3 \mathrm{~nm}\left(N_{3}\right)$ at the end of the ageing chamber. For heterogeneous nucleation, GSA, $\mathrm{COV}_{\mathrm{s}}$, and $N_{3 \text { fin }}$ are as for kinetic nucleation, but $K_{1}=3.8 \times 10^{-17}$ and $K_{2}=5.6 \times 10^{-17} \mathrm{~cm}^{3} \mathrm{~s}^{-1}$ for each case.

\begin{tabular}{l|lll|lll|l}
\hline Measured & \multicolumn{3}{|c|}{ Cluster activation } & \multicolumn{3}{|c|}{ Kinetic nucleation } & Measured \\
GSA $\left(\mathrm{cm}^{-3}\right)$ & $\mathrm{COV}_{\mathrm{s}}\left(\mathrm{cm}^{-3}\right)$ & $A\left(\mathrm{~s}^{-1}\right)$ & $N_{3 \mathrm{fin}}\left(\mathrm{cm}^{-3}\right)$ & $\mathrm{COV}_{\mathrm{s}}\left(\mathrm{cm}^{-3}\right)$ & $K\left(\mathrm{~cm}^{3} \mathrm{~s}^{-1}\right)$ & $N_{3 \mathrm{fin}}\left(\mathrm{cm}^{-3}\right)$ & $N_{3}\left(\mathrm{~cm}^{-3}\right)$ \\
\hline $2.76 \times 10^{9}$ & $6.00 \times 10^{10}$ & $2.00 \times 10^{-3}$ & $6.88 \times 10^{5}$ & $4.00 \times 10^{10}$ & $1.00 \times 10^{-12}$ & $6.84 \times 10^{5}$ & $7.69 \times 10^{5}$ \\
$3.41 \times 10^{9}$ & $8.00 \times 10^{10}$ & $2.00 \times 10^{-3}$ & $6.93 \times 10^{5}$ & $8.00 \times 10^{10}$ & $5.00 \times 10^{-13}$ & $7.52 \times 10^{5}$ & $1.03 \times 10^{6}$ \\
$1.36 \times 10^{10}$ & $1.25 \times 10^{12}$ & $1.00 \times 10^{-3}$ & $3.54 \times 10^{6}$ & $1.50 \times 10^{12}$ & $5.00 \times 10^{-14}$ & $3.16 \times 10^{6}$ & $3.13 \times 10^{6}$ \\
$4.17 \times 10^{10}$ & $1.50 \times 10^{12}$ & $5.50 \times 10^{-4}$ & $5.97 \times 10^{6}$ & $1.70 \times 10^{12}$ & $4.00 \times 10^{-15}$ & $5.08 \times 10^{6}$ & $4.61 \times 10^{6}$ \\
$1.53 \times 10^{11}$ & $1.60 \times 10^{12}$ & $2.00 \times 10^{-4}$ & $7.34 \times 10^{6}$ & $1.70 \times 10^{12}$ & $7.00 \times 10^{-16}$ & $5.79 \times 10^{6}$ & $5.33 \times 10^{6}$ \\
$4.40 \times 10^{11}$ & $1.80 \times 10^{12}$ & $9.00 \times 10^{-5}$ & $9.36 \times 10^{6}$ & $1.70 \times 10^{12}$ & $2.50 \times 10^{-16}$ & $7.10 \times 10^{6}$ & $6.57 \times 10^{6}$ \\
$2.01 \times 10^{12}$ & $1.00 \times 10^{12}$ & $2.50 \times 10^{-5}$ & $1.14 \times 10^{7}$ & $6.00 \times 10^{11}$ & $5.50 \times 10^{-17}$ & $9.52 \times 10^{6}$ & $8.03 \times 10^{6}$ \\
\hline
\end{tabular}

concentration $\mathrm{N}_{3}\left(2.9 \times 10^{8} \mathrm{~cm}^{-3}\right)$ strongly exceeds the measured value $8 \times 10^{6} \mathrm{~cm}^{-3}$.

When the raw-exhaust GSA concentration was $4.4 \times$ $10^{11} \mathrm{~cm}^{-3}$, AEROFOR predicted the maximum momentary nucleation rate of $3.9 \times 10^{4} \mathrm{~cm}^{-3} \mathrm{~s}^{-1}$ (Fig. S1 in the Supplement). Although nucleation continued for $2.2 \mathrm{~s}$, it was not able to produce enough new particles. The final modelled $\mathrm{N}_{3}$ was $6.8 \times 10^{5} \mathrm{~cm}^{-3}$, too small compared to the measured $\mathrm{N}_{3}$ of $6.6 \times 10^{6} \mathrm{~cm}^{-3}$. The sulfuric acid concentration was not sufficient to grow the nucleated particles to the measured $11.2 \mathrm{~nm}$ sizes. When increasing the $\mathrm{COV}_{\mathrm{s}}$ concentration up to $1 \times 10^{12} \mathrm{~cm}^{-3}$, the mean diameter of the core mode was close to the measured $21 \mathrm{~nm}$, however, the nucleation mode diameter $(9 \mathrm{~nm})$ was still too small. On the other hand, higher $\mathrm{COV}_{\mathrm{s}}$ concentrations let the core mode particles grow too much.

When the measured raw-exhaust GSA concentration was $1.53 \times 10^{11} \mathrm{~cm}^{-3}$, the model did not predict any newly formed particles. This is inconsistent with the measurements which showed that the volatile nucleation mode was present since the GSA concentration exceeded $1 \times 10^{10} \mathrm{~cm}^{-3}$ (Fig. S2). Thus, we can conclude that the BHN mechanism cannot explain the measurements.

\subsubsection{Cluster activation and kinetic nucleation}

The second set of simulations was performed by using the ACT mechanism for nine different initial GSA values selected from Fig. 2. The activation coefficient $A$ and the COVs concentration were varied to find the best agreement with the modelled and measured particle size distributions at the end of the ageing chamber. The changes in these parameters affected the particle size distributions at the end of the ageing chamber so that an increase in $A$ increased the nucleation mode particle concentration, whereas an increase in the $\mathrm{COV}_{\mathrm{S}}$ concentration shifted the nucleation mode to larger sizes and simultaneously slightly decreased the nucleation mode concentration. As an example, Fig. 4 presents the results for all nucleation mechanisms studied in this research for the $100 \%$ engine load when the GSA concentration was stabilized to $2.0 \times 10^{12} \mathrm{~cm}^{-3}$, and $\mathrm{COV}_{\mathrm{s}}=6 \times 10^{11} \mathrm{~cm}^{-3}$. Again, in the case when no condensable organic vapour was present, the nucleation mode and even the core mode did not sufficiently grow.

With the ACT mechanism nucleation is not suppressed but the formation of $1.5 \mathrm{~nm}$ clusters continues during the whole simulation time $2.7 \mathrm{~s}$ (Fig. S3). The formed clusters were activated to grow by sulfuric acid and $\mathrm{COV}_{\mathrm{s}}$; however, the growth by sulfuric acid alone was not sufficient (Fig. S3, dotted line). When the $\mathrm{COV}_{\mathrm{s}}$ was included, the $\mathrm{N}_{3}$ at the end of the ageing chamber was $9.3 \times 10^{6} \mathrm{~cm}^{-3}$, close to the measured value $6.6 \times 10^{6} \mathrm{~cm}^{-3}$. As seen from Fig. 4 , the model predicts higher concentration for the smallest particles of the nucleation mode than the measurements, thus indicating that the SMPS might underestimate the concentration of the particles smaller than $10 \mathrm{~nm}$. According to the manufacturer, the uncertainties in the SMPS measurement may be caused by the uncertainties in voltage and flow accuracy, scan time, bipolar charge distribution, CPC efficiency curve, DMA transfer function, working gas, diffusion losses, and sampling and conditioning issues. Unfortunately, in the studies reported by Arnold et al. (2012) and Rönkkö et al. (2013) the size distribution of smallest particles was not measured by other methods than by the SMPS, and thus experimental evidence on uncertainties in SMPS measurements of vehicle exhaust nanoparticles is an issue for future studies (see Kuuluvainen et al., 2015).

For the other initial GSA values, the model was able to predict the measured size distributions as well. The estimated $\mathrm{COV}_{\mathrm{s}}$ concentration was close to $10^{12} \mathrm{~cm}^{-3}$ except in the cases when practically no nucleation occurred, i.e. for the GSA concentration smaller than around $10^{10} \mathrm{~cm}^{-3}$. The results by Arnold et al. (2012, open diamonds in Fig. 4) indicate that at the $100 \%$ engine load the lower limit concentrations of all acidic gases (other than GSA) are $3 \times 10^{11}$ $2 \times 10^{12} \mathrm{~cm}^{-3}$ for the GSA concentrations of $4.4 . \times 10^{11}$ $2 \times 10^{12} \mathrm{~cm}^{-3}$. 
Based on our simulations, as the initial GSA concentration varied from $2.8 \times 10^{9}$ to $2 \times 10^{12} \mathrm{~cm}^{-3}$ the activation coefficient $A$ varied in the range of $2.5 \times 10^{-5}-2 \times 10^{-3} \mathrm{~s}^{-1}$ (Table 3 and Fig. 5a). Values 2 orders of magnitude smaller for $A$ have been found in the ambient field measurements (e.g. Sihto et al., 2006; Paasonen et al., 2010) and in the laboratory measurements (Sipilä et al., 2010). It should be noted that the exhaust-GSA concentrations are much higher than in the atmosphere, and the formation mechanism might be different as well. As seen from Table 3, the modelled total number concentrations (particles $>3 \mathrm{~nm}$ ) were in good agreement with the measurements.

By using the KIN mechanism, the kinetic coefficient $\mathrm{K}$ and condensable vapour concentration varied (Table 3 ). As an example, Fig. 4 presents the results for the $100 \%$ engine load with $K=5.5 \times 10^{-17} \mathrm{~cm}^{3} \mathrm{~s}^{-1}$ and $\operatorname{COV}_{\mathrm{s}}=6 \times 10^{11} \mathrm{~cm}^{-3}$. Also with this mechanism nucleation occurred continuously, but the nucleation rate decreased faster than with the ACT mechanism (Fig. S4). The concentrations of particles larger than $3 \mathrm{~nm}\left(\mathrm{~N}_{3}\right)$ and size distributions were in good agreement with the measurements (Table 3). However, sulfuric acid alone was not sufficient to grow the particles to the detectable sizes.

As with the ACT mechanism, the nucleation coefficient $K$ varied strongly as a function of the initial GSA concentration (Table 3 and Fig. 5b) with the KIN mechanism. However, during the steady state driving cycle (100\% engine load), the measured raw exhaust parameters such as temperature, $\mathrm{H}_{2} \mathrm{O}$ concentration, $\mathrm{RH}$, core and soot mode particle concentrations, were constant, only GSA varied, probably due to the storage effect in the ATS as mentioned in Sect. 2.3. Therefore, it was expected that the nucleation coefficients $A$ and $K$ should have constant values when simulating the different cases within the same engine load.

\subsubsection{Heteromolecular nucleation}

Finally, the fourth set of simulations was performed by assuming homogeneous heteromolecular nucleation between sulfuric acid and organic vapour molecules $\mathrm{COV}_{\mathrm{s}}$ ) along with the homogeneous homomolecular nucleation of sulfuric acid. Paasonen et al. (2010) suggested that, besides organic vapours participate in the initial growth of the nucleated particles, they might also be involved in the nucleation process itself. The idea was recently supported by the results of the chamber measurements (e.g. Dal Maso et al., 2014).

The nucleation coefficients $K_{1}$ and $K_{2}$ of the HET mechanism were parameterized by using the results from the KIN mechanism, i.e. statistically by making a least square fit for the equation

$$
K[\mathrm{GSA}]^{2}=K_{1}[\mathrm{GSA}]^{2}+K_{2}[\mathrm{GSA}]\left[\mathrm{COV}_{\mathrm{s}}\right],
$$

where we assumed that the nucleation rates by the kinetic theory (left-hand side) and by the heteromolecular nucleation theory (right-hand side) were equal. This procedure resulted
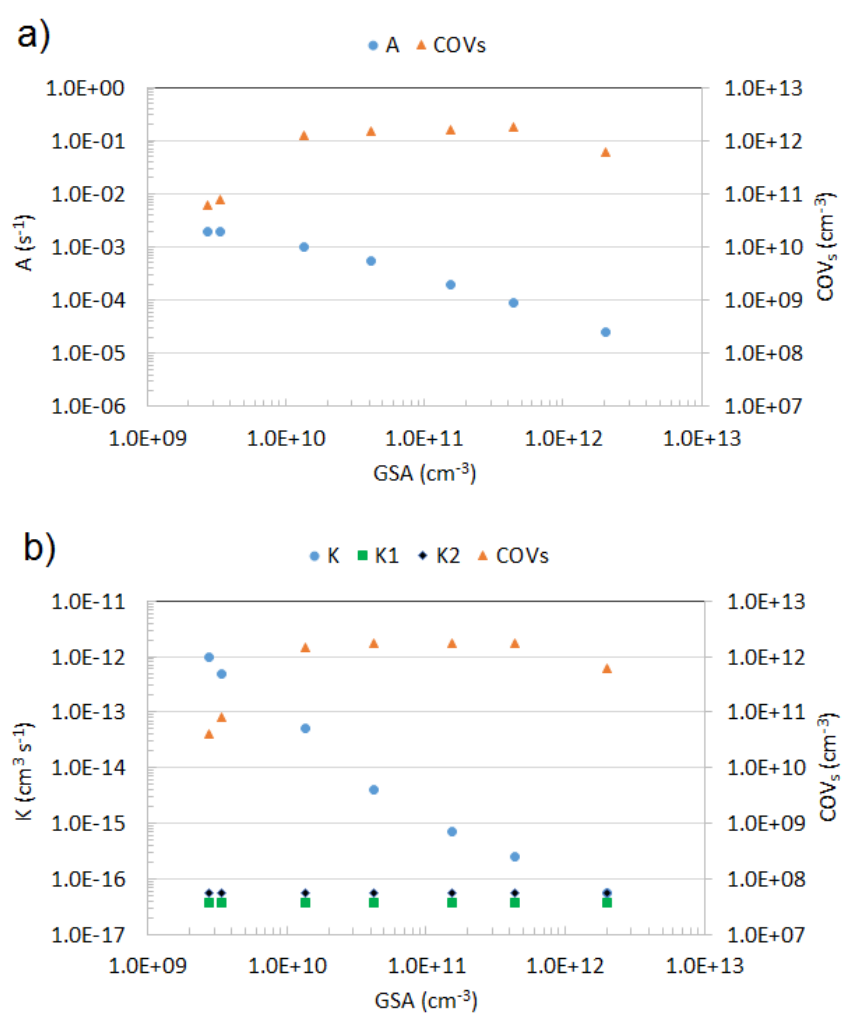

Figure 5. Nucleation coefficients as a function of GSA and $\mathrm{COV}_{\mathrm{S}}$ concentrations when the nucleation mechanism was ACT (a), KIN and HET (b).

in constant values of $3.8 \times 10^{-17}$ and $5.6 \times 10^{-17} \mathrm{~cm}^{3} \mathrm{~s}^{-1}$ for $\mathrm{K}_{1}$ and $\mathrm{K}_{2}$, respectively, independently of the initial GSA concentration, whereas the ACT and KIN mechanisms could not (Fig. 5).

The GSA and $\mathrm{COV}_{\mathrm{s}}$ concentrations for the HET nucleation (used in Eq. 4) were the same as for the KIN nucleation given in Table 3. Interestingly, the $\mathrm{COV}_{\mathrm{s}}$ concentration was almost constant, around $1.7 \times 10^{12} \mathrm{~cm}^{-3}$, except for the two lowest GSA cases in which no nucleation occurred, and with the extremely high GSA concentration, which alone allowed the particles to grow notably. However, the sensitivity of particle number size distribution against the $\mathrm{COV}_{\mathrm{s}}$ concentration will be presented in Sect. 3.3.2.

Although both nucleation and condensation consumed the $\mathrm{COV}_{\mathrm{s}}$, its high concentration ensured that the size distribution with the initial GSA $=2.0 \times 10^{12} \mathrm{~cm}^{-3}$ and $\mathrm{COV}_{\mathrm{s}}=$ $6.0 \times 10^{11} \mathrm{~cm}^{-3}$ remained the same as presented for the KIN mechanism where $\mathrm{COV}_{\mathrm{S}}$ was consumed only by condensation (Fig. 4). This case is named hereafter the base case.

By using the same $K_{1}$ and $K_{2}$ values for the other initial GSA values (Table 3 ) the model was able to predict the size distributions which were in good agreement with the experiments. The modal mean diameters of the volatile nucleation mode coincided with the measured ones even though the model predicted stronger NUP formation than measured 

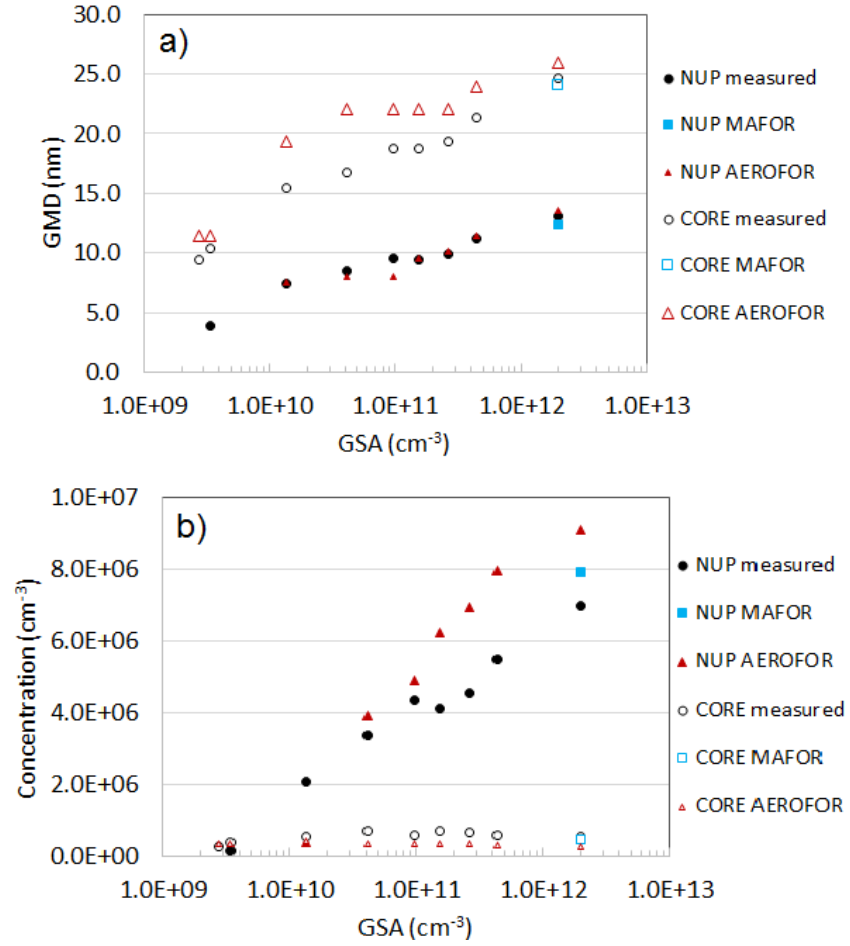

Figure 6. Mean diameters (GMD) (a) and number concentration of particles $>3 \mathrm{~nm}$ (b) at the end of the simulation for the volatile nucleation mode and the core mode. The nucleation mechanism was HET. Also shown are the measured values at the end of the ageing chamber.

if the GSA concentration exceeded $10^{11} \mathrm{~cm}^{-3}$ (Fig. 6). In regard to the core mode, the model overestimated the growth of particles and slightly underestimated their number concentration. The reason might be overly high water content of these non-volatile particles in the model. On the other hand, the SMPS measured mobility diameters which do not grow in spite of substantial condensation occurs if the particles are fractal-like as soot particles. We cannot exclude the possibility of fractal structure of core particles, or condensation of organic vapours other than the nucleating vapour.

The MAFOR model with somewhat different organic condensation processes predicted well the GMDs and number concentrations in the base case but underestimated the NUP concentrations at GSA below $1 \times 10^{11} \mathrm{~cm}^{-3}$. The particle distribution in MAFOR is initially non-hygroscopic (nonvolatile core and soot particles) and becomes increasingly hygroscopic through condensation of GSA and $\mathrm{COV}_{\mathrm{s}}$.

\subsection{Mass size distribution}

As mentioned above, additional model simulations for the base case (raw exhaust GSA $=2 \times 10^{12} \mathrm{~cm}^{-3}$ ) were carried out by the MAFOR model. With MAFOR it is possible to track the mass composition of each size bin during the simulation. Figure 7 shows the time development of the number

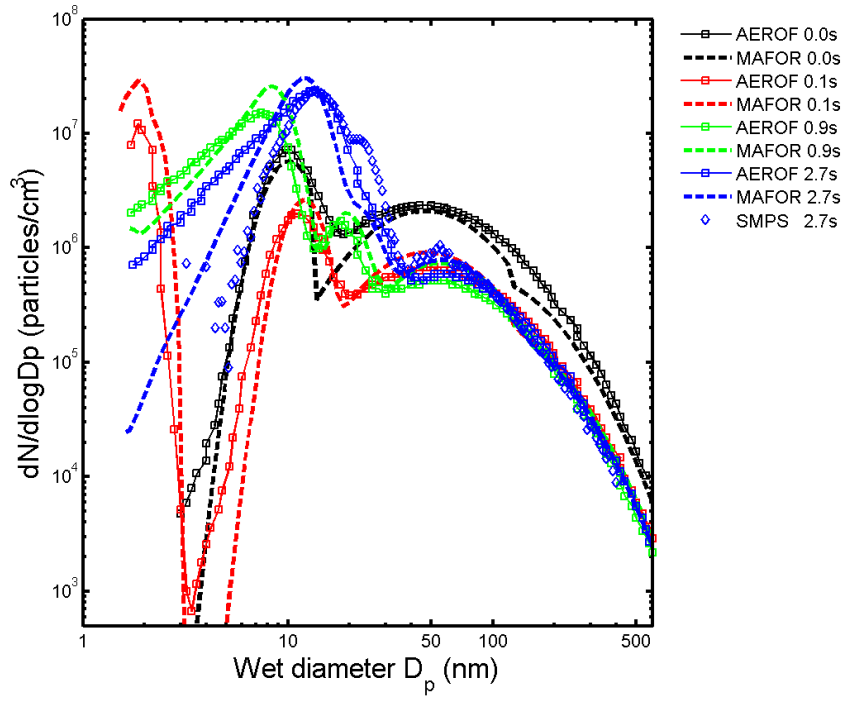

Figure 7. Number size distribution $\left(\mathrm{d} N / \mathrm{d} \log D_{\mathrm{p}}\right.$ in particles $\left.\mathrm{cm}^{-3}\right)$ at different stages of the exhaust $(t=0.0 \mathrm{~s}$, black lines; $t=0.1 \mathrm{~s}$, red lines; $t=0.9 \mathrm{~s}$, green lines; $t=2.7 \mathrm{~s}$, blue lines) as modelled by AEROFOR (lines with open squares) and by MAFOR (dashed lines) together with the SMPS measurement at $2.7 \mathrm{~s}$ (blue open diamonds). Initial size distribution with the core mode at $10 \mathrm{~nm}$ and soot mode at $49 \mathrm{~nm}$. The nucleation mechanism for these simulations was HET.

size distribution and Fig. 8 the mass and composition size distributions. The initial raw exhaust particle distribution at $t=0.0 \mathrm{~s}$ was assumed to be entirely non-hygroscopic. It was divided into the core mode between $5-15 \mathrm{~nm}$ consisting of non-volatile organic matter $\left(\mathrm{OM}_{\mathrm{nv}}\right)$ and the soot mode consisting of elemental carbon. With the initial concentrations of $\mathrm{COV}_{\mathrm{s}}$ and $\mathrm{COV}_{1}$ of $2.7 \times 10^{12} \mathrm{~cm}^{-3}$ and $5.0 \times 10^{12} \mathrm{~cm}^{-3}$, respectively, MAFOR predicted the mean modal diameter of the volatile mode after $2.7 \mathrm{~s}$ simulation in good agreement with the observed one. The initial concentration of $\mathrm{COV}_{\mathrm{S}}$ was higher than in the base case simulation with AEROFOR $\left(\mathrm{COV}_{\mathrm{s}}=6.0 \times 10^{11} \mathrm{~cm}^{-3}\right)$, likely due to the different hygroscopic properties of $\mathrm{COV}_{\mathrm{s}}$ used in the models. The hygroscopic properties of $\mathrm{COV}_{\mathrm{S}}$ in MAFOR were that of sodium succinate, and due to low RH $(<16 \%)$ in the experiment $\mathrm{COV}_{\mathrm{s}}$ did not take up water. In addition to $\mathrm{COV}_{\mathrm{s}}, \mathrm{COV}_{1}$ was needed in MAFOR to predict the observed growth as discussed in Sect. 2.2.

During the dilution stage, rapid nucleation of GSA and $\mathrm{COV}_{\mathrm{S}}$ occurred to form a new volatile particle mode with GMD at $\sim 2 \mathrm{~nm}$ at $0.1 \mathrm{~s}$ (red lines in Fig. 7). By condensation of sulfuric acid and $\mathrm{COV}_{\mathrm{s}}$, the exhaust particles became more hygroscopic. The growth of the volatile nucleation mode was promoted by condensation of $\mathrm{COV}_{1}$ in the MAFOR simulation. Core mode composition at $0.1 \mathrm{~s}$ (mass fraction in percentage) was $4.5 \% \mathrm{OM}_{\mathrm{nv}}, 18.9 \%$ sulfuric acid, $2.1 \%$ semivolatile organic matter $\left(\mathrm{OM}_{\mathrm{s}}\right), 32.2 \%$ extremely low-volatile organic matter $\left(\mathrm{OM}_{1}\right)$, and $41.3 \%$ water. In the ageing cham- 

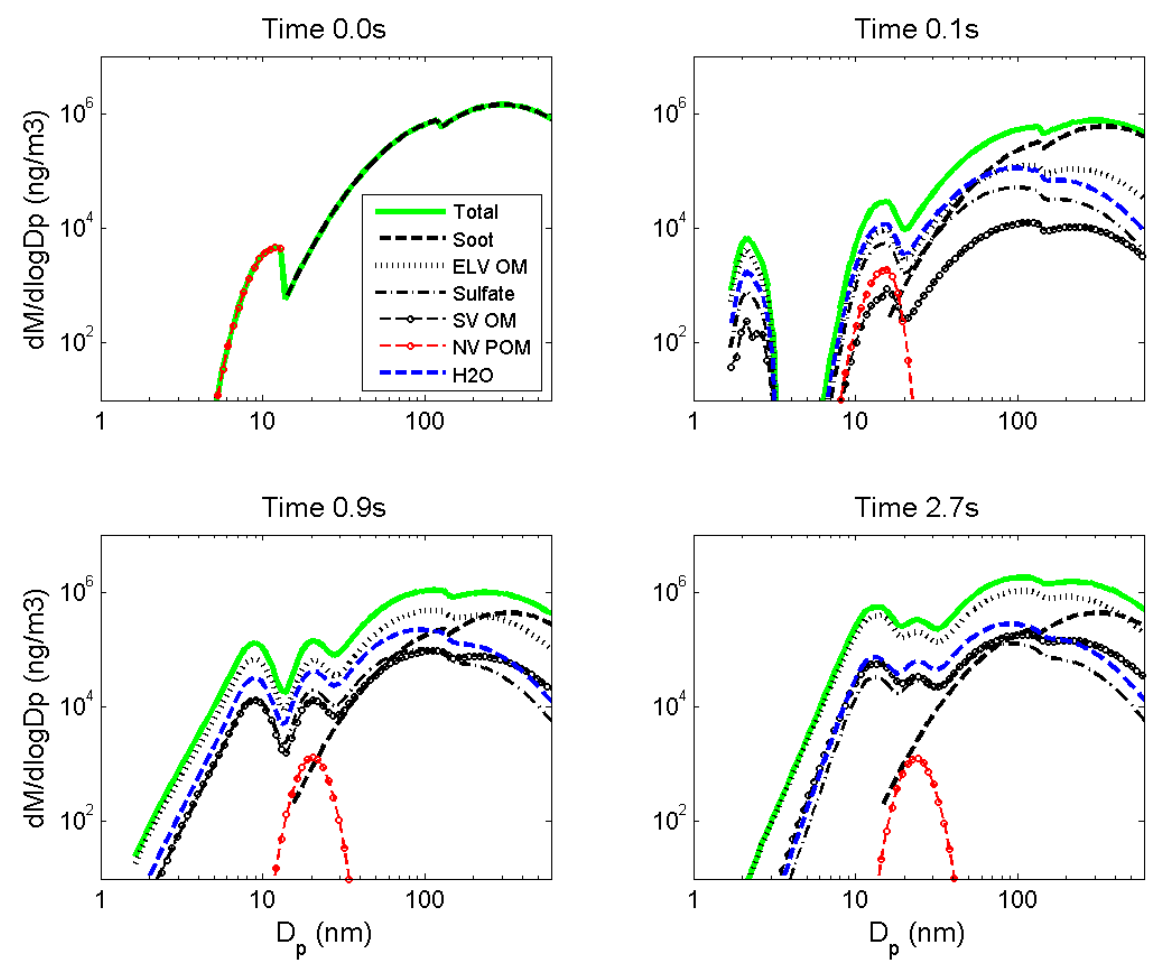

Figure 8. Mass composition distribution $\left(\mathrm{d} M / \mathrm{d} \log D_{\mathrm{p}}\right.$ in $\left.\mathrm{ng} \mathrm{m}^{-3}\right)$ at different stages of the exhaust (initial at $t=0.0 \mathrm{~s}$, after dilution $t=0.1 \mathrm{~s}$, in the ageing chamber $t=0.9 \mathrm{~s}$, and final $t=2.7 \mathrm{~s}$ ) modelled by MAFOR. Includes the total mass concentration (green line) and the mass distributions of non-volatile organic matter $\left(\mathrm{OM}_{\mathrm{nv}}\right.$, red dashed line with open circles), soot (black dashed line), sulfuric acid (black dashdotted line), semi-volatile organic matter $\left(\mathrm{OM}_{\mathrm{s}}\right.$, black dashed line with open circles), extremely low-volatile organic matter $\left(\mathrm{OM}_{1}\right)$ as well as the mass distribution of water (blue dashed line). The nucleation mechanism for these simulations was HET.

ber, the volatile and core modes grew further by condensation of GSA, $\mathrm{COV}_{\mathrm{s}}, \mathrm{COV}_{1}$ and water. Nucleation by the HET mechanism continuously produced new particles which were scavenged or grown to larger particles. The total particle mass increased from $3.5 \mu \mathrm{g} \mathrm{m}^{-3}$ at $0.1 \mathrm{~s}$ to $28.2 \mu \mathrm{g} \mathrm{m}^{-3}$ at $0.9 \mathrm{~s}$, and further to $116.8 \mu \mathrm{g} \mathrm{m}^{-3}$ after $2.7 \mathrm{~s}$. At $0.9 \mathrm{~s}$ GMD of the volatile mode and core mode increased to $8-9 \mathrm{~nm}$ and $\sim 20 \mathrm{~nm}$, respectively. The percentage mass fraction of condensed organic matter increased to $55.5 \%$ while that of water and sulfuric acid decreased to 29.9 and $13.7 \%$, respectively.

At the end of the simulation (2.7 s) the measured GMDs of the volatile and core modes were 13.1 and $24.7 \mathrm{~nm}$, respectively, closely matched by the models. Both models underestimated particle number concentrations of the core mode.

The modelled mass fractions of the final exhaust particle composition are given in Table 4. According to MAFOR, the final mode of particles with a non-volatile core consisted of $78.0 \%$ condensed organic matter, $6.8 \%$ sulfuric acid and $15.0 \%$ water. The ratio $\mathrm{OM}_{1} / \mathrm{OM}_{\mathrm{S}}$ decreased from the volatile nucleation mode to the soot mode (volatile nucleation mode: 6.82 ; core mode: 6.55 ; soot mode: 5.74 ) since uptake of $\mathrm{COV}_{\mathrm{s}}$ to the nucleation mode was more limited by the Kelvin effect than uptake of $\mathrm{COV}_{1}$ due to its extremely low vapour pressure. The decreasing trend of $\mathrm{OM}_{1} / \mathrm{OM}_{\mathrm{s}}$ was
Table 4. Mass fractions of particle components at $2.7 \mathrm{~s}$ obtained from simulation by MAFOR with initial GSA $=2 \times 10^{12} \mathrm{~cm}^{-3}$. $\mathrm{OM}_{\mathrm{s}}, \mathrm{OM}_{1}$ and $\mathrm{OM}_{\mathrm{nv}}$ refer to semi-volatile, low volatile and nonvolatile organic matter.

\begin{tabular}{lrrr}
\hline & $\begin{array}{r}\text { Volatile nucleation } \\
\text { mode }\end{array}$ & $\begin{array}{r}\text { Core } \\
\text { mode }\end{array}$ & $\begin{array}{r}\text { Soot } \\
\text { mode }\end{array}$ \\
\hline $\mathrm{H}_{2} \mathrm{O}$ & 0.128 & 0.150 & 0.116 \\
$\mathrm{H}_{2} \mathrm{SO}_{4}$ & 0.058 & 0.068 & 0.053 \\
$\mathrm{OM}_{\mathrm{S}}$ & 0.104 & 0.103 & 0.092 \\
$\mathrm{OM}_{1}$ & 0.710 & 0.676 & 0.531 \\
$\mathrm{OM}_{\mathrm{nv}}$ & 0.000 & 0.002 & 0.000 \\
$\mathrm{SOOT}$ & 0.000 & 0.000 & 0.208 \\
\hline TOT & 1.000 & 1.000 & 1.000 \\
\hline
\end{tabular}

rather moderate, because the uptake of $\mathrm{COV}_{\mathrm{S}}$ was only affected by the Kelvin effect for particles $<3 \mathrm{~nm}$ which do not significantly contribute to the mass. Initially present nonvolatile organic particles formed the nuclei for the condensation of gas-phase vapours in the core mode. However, $\mathrm{OM}_{\mathrm{nv}}$ contributed negligible to the final mass of the core mode. MAFOR probably underestimated the water content 

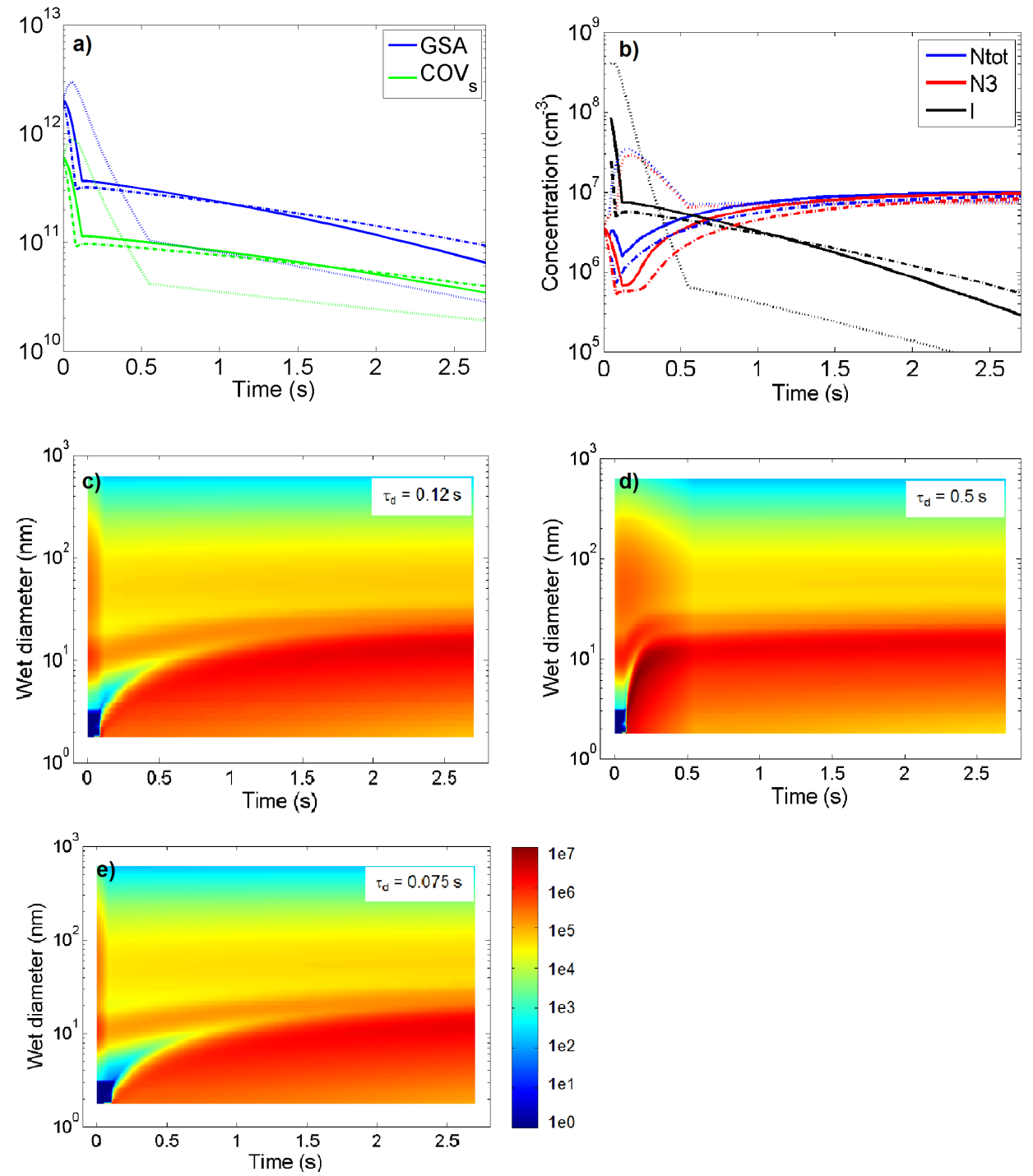

Figure 9. Effects of time constant $\left(\tau_{\mathrm{d}}\right)$ on time evolution of gases (a), particle number and nucleation rate (b) and number size distribution (c)-(e), where particle number concentration in $\mathrm{cm}^{-3}$ is shown by colour bar. In (a) and (b), solid curves refer to $\tau_{\mathrm{d}}=0.12 \mathrm{~s}$ (base case), dotted curves to $\tau_{\mathrm{d}}=0.5 \mathrm{~s}$, and dash-dotted curves to $\tau_{\mathrm{d}}=0.075 \mathrm{~s}$. The nucleation mechanism for these simulations was HET.

of the exhaust particles by assuming that $\mathrm{COV}_{1}$ was nonhygroscopic.

\subsection{Sensitivity analysis}

The sensitivity of particle number size distribution against the dilution time constant, condensable organic vapour concentration, and engine load were tested by AEROFOR for the base case.

\subsubsection{Effects of dilution time constant}

After $0.1 \mathrm{~s}$ the exhaust enters the ageing chamber. If the dilution time constant $\tau_{\mathrm{d}}$ increases from $0.12 \mathrm{~s}$ (base case) to e.g. $0.5 \mathrm{~s}$, the dilution of exhaust gases continues further in the ageing chamber than for the base case. It should be noted that dilution only occurs when the simulation time is less than $\tau_{\mathrm{d}}$. Due to the slower momentary dilution rate, the gas concentrations are at first higher leading to stronger nucleation and new particle formation (Fig. 9). However, simultaneously the condensation sink of pre-existing and nucleated particles grows, consuming both gases more efficiently, and after $0.4 \mathrm{~s}$ from the beginning the gas concentrations and nucleation rate become lower than those of the base case. After that the growth rate of particle number concentration depletes and stabilizes to a somewhat smaller number as in the base case. Figure $9 \mathrm{c}$ shows that in general, the modal sizes of the final distribution are rather close to that of the base case but their concentrations are lower.

When the time constant decreases to $0.075 \mathrm{~s}$, all dilution occurs before the exhaust enters into the ageing chamber. 
This leads to a very fast reduction of the gas concentrations, and subsequently decreases the nucleation and total condensation. Therefore, the final gas concentrations remain higher unlike the particle concentration and their sizes that are smaller than in the base case. The laboratory studies by Mathis et al. (2004) showed that dilution conditions such as the dilution ratio, temperature and relative humidity of the dilution air strongly affect the formation of volatile nucleation mode.

\subsubsection{Effects of condensable organic vapour}

The used initial $\mathrm{COV}_{\mathrm{s}}$ concentrations were $10^{10} \mathrm{~cm}^{-3}$ and $10^{12} \mathrm{~cm}^{-3}$. Figure S5 illustrates the number size distribution as a function of $\mathrm{COV}_{\mathrm{s}}$ concentration. As expected, an increase in $\mathrm{COV}_{\mathrm{S}}$ concentration increases the nucleation rate and new particle production. Simultaneously, the enhanced condensation of GSA and $\mathrm{COV}_{\mathrm{s}}$ consumes these vapours, and after $1.2 \mathrm{~s}$ the nucleation rate dramatically drops, the particle number concentration stabilizes, but particles still continue growing in size. All in all, the final nucleation mode accounts for too many particles, around 3-fold compared with the base case, and besides this mode has grown so much that it totally covers the core mode. In fact, the geometric mean diameter of the mode was doubled up to $25 \mathrm{~nm}$. The situation is vice versa, if the $\mathrm{COV}_{\mathrm{s}}$ concentrations is decreased. The nucleated particle concentration remains too low and they do not grow sufficiently to reach the measured sizes.

With MAFOR we tested how much the different concentrations of $\mathrm{COV}_{\mathrm{s}}$ and $\mathrm{COV}_{1}$ influenced the particle number size distribution evolution. When the $\mathrm{COV}_{1}$ concentration was reduced from $5.0 \times 10^{12} \mathrm{~cm}^{-3}$, the GMD of the volatile mode of the size distribution after $2.7 \mathrm{~s}$ shifted to a smaller size and the maximum concentration of that mode was lower than in the base case. Figure S6 depicts the case when $\mathrm{COV}_{1}$ was set to zero (green line). In that case MAFOR predicted the GMD of $10.7 \mathrm{~nm}$ for the volatile mode, whereas the measured value was $13.1 \mathrm{~nm}$. When MAFOR used the same hygroscopic properties for $\mathrm{COV}_{\mathrm{s}}$ as AEROFOR, the water uptake of $\mathrm{COV}_{\mathrm{s}}$ was similar to sulfuric acid (red line in Fig. S6); the resulting GMD of the volatile mode was in agreement with AEROFOR and with the measured diameter. The differences for the number concentration of small particles below $9 \mathrm{~nm}$ diameter were probably due to higher coagulation rates in MAFOR. In both tests, the growth of large particles (>200 nm diameter) was overestimated due to the enhanced water uptake of the soot mode. When the Kelvin effect was excluded for $\mathrm{COV}_{\mathrm{s}}$ in the latter case, there were little or no particles below $3 \mathrm{~nm}$ because these nucleated particles were able to grow to larger sizes by passing the Kelvin barrier (Fig. S6, dotted black line). Consequently, the volatile mode showed a little higher maximum peak concentration compared to the case when the Kelvin effect was included.

\subsubsection{Effects of pre-existing non-volatile core particles}

The base case simulation was repeated for different concentrations of initial soot and core particles. As mentioned earlier, these non-volatile particles were formed during the combustion process, and engine technology along with combustion optimization, fuel and lubricant oil compositions, after-treatment systems, and engine load affect their formation and concentrations. Lähde et al. (2010) found out that while the non-volatile soot mode concentration decreased, the non-volatile nucleation mode concentration increased for a heavy duty diesel engine. In these simulations the initial non-volatile soot mode concentration varied between $1.1 \times 10^{6}$ and $6.8 \times 10^{7} \mathrm{~cm}^{-3}$, and the soot mode between $2.6 \times 10^{5}$ and $1.5 \times 10^{7} \mathrm{~cm}^{-3}$ (Fig. 10a) while the geometric mean diameters and standard deviations of the modes remained constant as given by Table 1 .

Figure 10b shows the nucleated particle (NUP) concentration at the end of the ageing chamber as a function of the condensation sink (CS) of pre-existing soot and core particles. The NUP concentration was manually calculated or if possible, determined by fitting three modes on the final size distribution (Hussein et al., 2005). It is obvious that while the CS decreases the NUP concentration increases. If $\mathrm{CS} \geq 1 \mathrm{~s}^{-1}$, the NUP concentrations linearly depend on the logarithm of the CS. This occurs if the initial dry soot mode concentration is larger than $1.0 \times 10^{6} \mathrm{~cm}^{-3}$ and the core mode concentration larger than $1.5 \times 10^{7} \mathrm{~cm}^{-3}$. It should be noted that due to small sizes the effect of the core mode on the CS is small indeed. The maximum NUP concentration is $1.7 \times 10^{7} \mathrm{~cm}^{-3}$ when the CS is zero. This corresponds to cases in which vehicles are equipped with modern diesel particle filters (DPF), the efficiency of those in solid particle number reduction is nowadays even $99.9 \%$. The NUP formation is ceased if the $\mathrm{CS}$ is as high as $52 \mathrm{~s}^{-1}$. This occurs if the soot mode and core mode concentrations at hot exhaust $(696 \mathrm{~K})$ are for example, $6.8 \times 10^{7}$ and $2.6 \times 10^{5} \mathrm{~cm}^{-3}$, respectively, with the modal sizes as given in Table 1 .

These results also indicate that a reduction in non-volatile particle concentrations as a result of modern engines and particle filters actually enhance nucleation and volatile particle emissions as also discovered by $\mathrm{Du}$ and $\mathrm{Yu}$ (2006).

\subsubsection{Effects of engine load}

Driving conditions at 100 and $75 \%$ engine loads had minor effects on the number concentrations of soot mode and core mode particles (Table 1), whereas at $50 \%$ engine load the soot mode concentration was significantly lower and core mode concentration higher than at the higher loads leading to much lower condensation sink of $2.5 \mathrm{~s}^{-1}$ (Fig. 10b). Additionally, due to lower temperatures at lower loads the $\mathrm{SO}_{2}$ to $\mathrm{SO}_{3}$ conversion in the catalyst is less efficient, and subsequently the GSA concentration remains lower, in the stabilized phase $3 \times 10^{11} \mathrm{~cm}^{-3}$ (Fig. 2). This, in turn, led to lower 

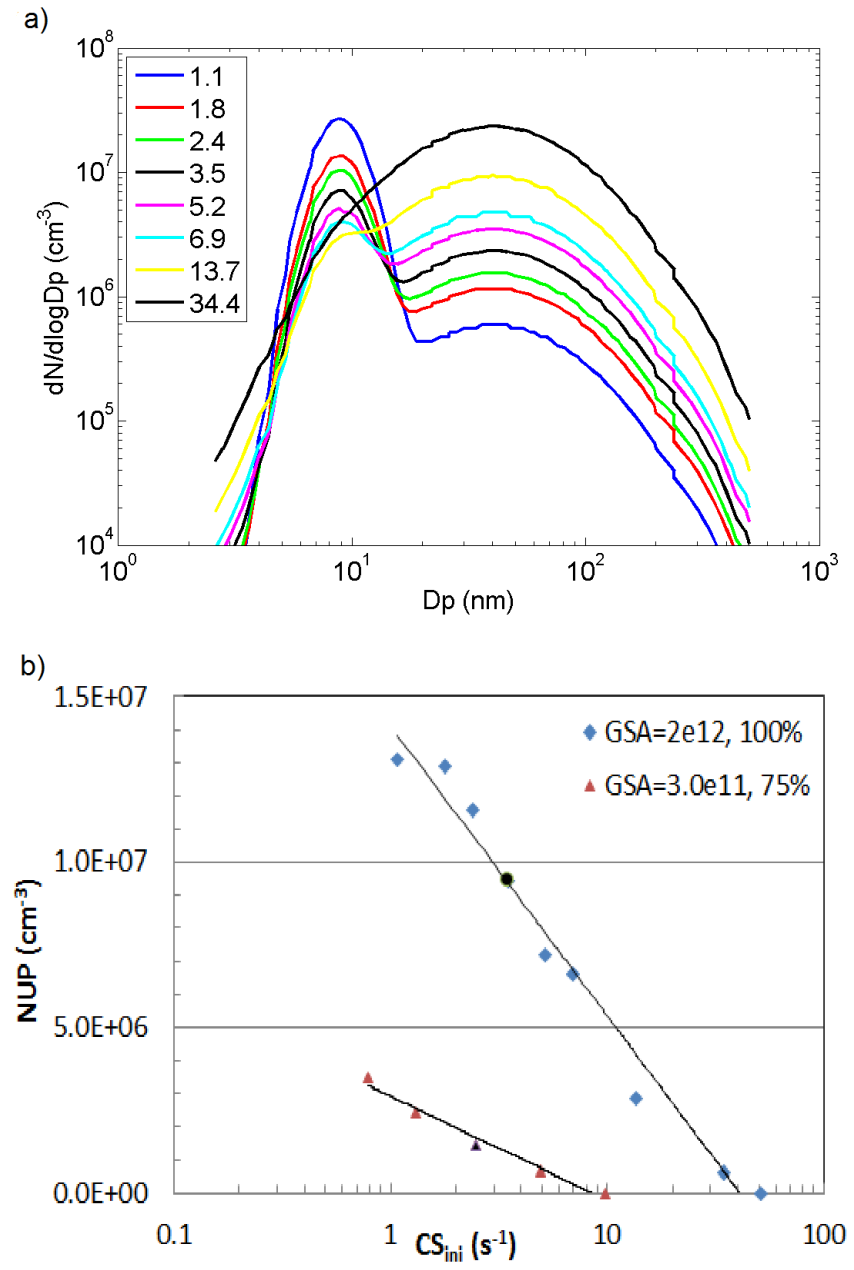

Figure 10. (a) Initial soot and core mode concentrations. The legend shows the corresponding condensation sinks in $\mathrm{s}^{-1}$. (b) Nucleated particle concentration (NUP) at the end of the simulation as a function of initial condensation sink for $100 \%$ engine load with $\mathrm{GSA}=2 \times 10^{12} \mathrm{~cm}^{-3}$ and raw exhaust $T=697 \mathrm{~K}$. Also shown in (b) are the results for $75 \%$ engine load with GSA $=3 \times 10^{11} \mathrm{~cm}^{-3}$ and raw exhaust $T=657 \mathrm{~K}$. Black dots refer to base cases.

NUP formation, in maximum $3.4 \times 10^{6} \mathrm{~cm}^{-3}$ at the end of the simulation. At a $50 \%$ engine load no NUP formation was predicted.

\subsection{Effect of FSC}

The aim of the last set of simulations was to find the initial GSA concentration when nucleation is ceased at $100 \%$ engine load $(T=697 \mathrm{~K})$ for the base case $\left(\mathrm{CS}=3.5 \mathrm{~s}^{-1}\right)$ and for the case when all non-volatile particles were filtered $\left(\mathrm{CS}=0 \mathrm{~s}^{-1}\right)$. The highest GSA value of $2 \times 10^{12} \mathrm{~cm}^{-3}$ was reached when the engine was operated by diesel with the FSC of $36 \mathrm{ppm}$ (Fig. 11). It should be noted that the GSA concentration also depends on the sulfur content of the lubricant oil. If the DPF was used, the NUP concentration

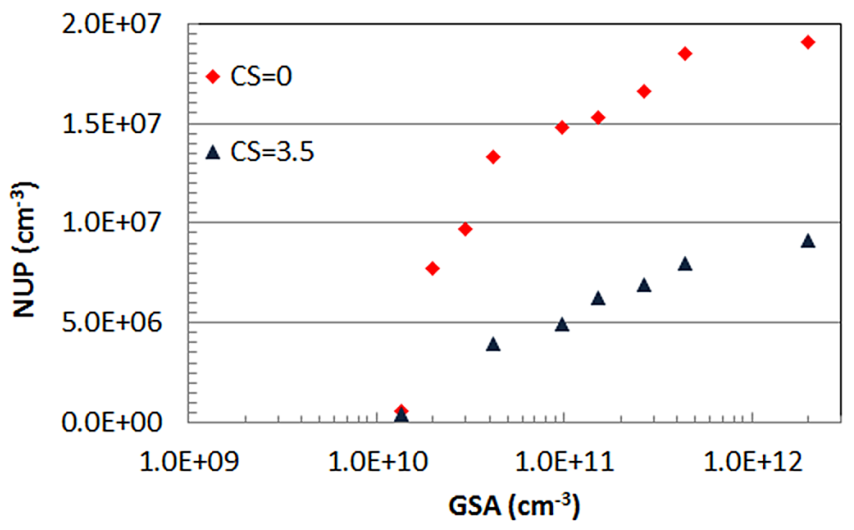

Figure 11. Nucleated particle concentration (NUP) at the end of the simulation as a function of the initial GSA concentration for $100 \%$ engine load. The initial core and soot mode concentrations were as in the base case $\left(\mathrm{CS}=3.5 \mathrm{~s}^{-1}\right)$ or zero $\left(\mathrm{CS}=0 \mathrm{~s}^{-1}\right)$. The nucleation mechanism for these simulations was HET.

was $1.9 \times 10^{7} \mathrm{~cm}^{-3}, 2$ times higher than for the pDPF. In both cases, the predicted NUP concentrations decreased with lower GSA concentrations, and ceased when the GSA concentration was around $10^{10} \mathrm{~cm}^{-3}$. This value corresponds to the usage of biofuel with FSC $<1$ ppm as seen from Fig. 3 in Arnold et al. (2012). On the other hand, the GSA concentration of $3 \times 10^{11} \mathrm{~cm}^{-3}$ was measured by Arnold et al. (2012) when the FSC was $6 \mathrm{ppm}$. As seen from Fig. 11, the NUP formation does not depend linearly on the GSA concentration. For example, when decreasing the GSA concentration by $85 \%$ from $2 \times 10^{12}$ to $3 \times 10^{11} \mathrm{~cm}^{-3}$ the NUP concentrations decreases only $15-25 \%$.

\section{Concluding remarks}

Although our model simulations cover the exhaust particle formation and growth during the laboratory sampling, the results might be generalized to concern the atmospheric conditions as well. It is well-known that nucleation mode formation at the laboratory tests is very sensitive to the dilution conditions (Khalek et al., 2003; Mathis et al., 2004). However, our on-road and laboratory measurements (Rönkkö et al., 2006, 2007) showed that the volatile nucleation mode was already formed in the atmosphere in less than $0.7 \mathrm{~s}$, at closer than $10 \mathrm{~m}$ distance from the exhaust pipe, and that the dilution system along with the ageing chamber used in these measurements mimics reasonably well the real-world conditions and size distributions measured on-road. The exhaust plume age of $0.4-0.7 \mathrm{~s}$ in the atmosphere corresponds to the atmospheric dilution ratio of approximately 200-400 (Kittelson et al., 1998).

The aerosol dynamics models used in this research are process models that describe the main aerosol processes in details. They use sectional representations for particle size dis- 
tributions with at least 100 size sections to prevent numerical diffusion and are free from assumptions of lognormal particle modes that are used in modal models. Several nucleation mechanisms and their potential to predict particle formation in diesel exhaust were investigated. The best fit with the measurements was predicted by the HET nucleation mechanism in which both sulfuric acid and semi-volatile organic acid molecules participate. Nucleation occurred continuously in the ageing chamber producing stable clusters of $1.5 \mathrm{~nm}$ in size. Due to the competition of coagulation and condensation, these freshly formed particles were scavenged or grew to larger sizes. The nucleation rate decreased as a function of elapsed time due to the increased condensation sink and subsequent reduction of the nucleating vapours. However, at the end of the simulation at $2.7 \mathrm{~s}$, the model predicted $2.8 \times 10^{5}$ particles per $\mathrm{cm}^{3}$ in the size range of $1.5-3 \mathrm{~nm}$ at $100 \%$ engine load, and $3.0 \times 10^{5} \mathrm{~cm}^{-3}$ at $75 \%$ engine load. These results lead to a hypothesis that diesel exhaust might yield a reservoir of small clusters that might be activated to grow to even cloud condensation nuclei $(\mathrm{CCN})$ sizes if sufficient amounts of condensable vapours are present.

According to the model simulations, it was discovered that the semivolatile organic vapour $\mathrm{COV}_{\mathrm{s}}$ mostly accounted for the nucleation particle growth since GSA alone was not sufficient. MAFOR predicted that the aged exhaust particles contained 9-10\% $\mathrm{COV}_{\mathrm{s}}$ and 6-7\% sulfuric acid in terms of mass. The required $\mathrm{COV}_{\mathrm{s}}$ concentrations in both models were as high as $(0.6-1.8) \times 10^{12} \mathrm{~cm}^{-3}$ in the raw exhaust. In that case, the modern DOC does not totally prevent the formation of organic condensable vapours. The $\mathrm{COV}_{\mathrm{S}}$ concentration at the end of the simulation was around $1.1 \times 10^{11} \mathrm{~cm}^{-3}$ at $100 \%$ engine load and $6.5 \times 10^{10} \mathrm{~cm}^{-3}$ at $75 \%$ engine load. This indicates that diesel exhaust also emits precursor vapours for secondary organic aerosol as reported by Robinson et al. (2007).

Despite the recognized health and climate effects of particle emissions the volatile nucleation mode particles emitted from diesel engines are not regulated. To fulfill the Euro VI standards new diesel vehicles have to be equipped with DPFs which remove core and soot mode particles. However, based on the model simulations the NUP concentration at high load can be $1.7 \times 10^{7} \mathrm{~cm}^{-3}$ if the raw-exhaust GSA concentration was $2 \times 10^{12} \mathrm{~cm}^{-3}$. The GSA concentration depends not only on the sulfur content of fuel and lubricant oil, but also on the driving history of the engine. Decreasing the FSC from $36 \mathrm{ppm}$ to $6 \mathrm{ppm}$ the GSA concentration decreased $85 \%$ from $2 \times 10^{12}$ to $3 \times 10^{11} \mathrm{~cm}^{-3}$, and the subsequent decrease in the NUP concentration was $15-25 \%$. The NUP formation was in practice suppressed if the GSA concentration was below $10^{10} \mathrm{~cm}^{-3}$. This requires the use of biofuel. Also the development of lubricant oil additives might reduce their sulfur content and subsequent particle emissions.

\section{The Supplement related to this article is available online at doi:10.5194/acp-15-10435-2015-supplement.}

Acknowledgements. This research was a part of the TREAMproject and supported by the Finnish Funding Agency for Technology and Innovation (TEKES), AGCO Power, Neste Oil, Dinex Ecocat and Oy Nanol Technologies Ab.

Edited by: K. Lehtinen

\section{References}

Albriet, B., Sartelet, K. N., Lacour, S., Carissimo, B., and Seigneur, C.: Modelling aerosol number distributions from a vehicle exhaust with an aerosol CFD model, Atmos. Environ,, 44, 11261137, 2010.

Alföldy, B., Gieschaskiel, B., Hofmann, W., and Drossinos, Y.: Size-distribution dependent lung deposition of diesel exhaust particles. J. Aerosol Sci., 40, 652-663, 2009.

Almeida, J., Schobesberger, S., Kürten, A., Ortega, I. K., Kupiainen-Määttä, O., Praplan, A. P., Adamov, A., Amorim, A., Bianchi, F., Breitenlechner, M., David, A., Dommen, J., Donahue, N. M., Downard, A., Dunne, E., Duplissy, J., Ehrhart, S., Flagan, R. C., Franchin, A., Guida, R., Hakala, J., Hansel, A., Heinritzi, M., Henschel, H., Jokinen, T., Junninen, H., Kajos, M., Kangasluoma, J., Keskinen, H., Kupc, A., Kurtén, T., Kvashin, A. N., Laaksonen, A., Lehtipalo, K., Leiminger, M., Leppä, J., Loukonen, V., Makhmutov, V., Mathot, S., McGrath, M. J., Nieminen, T., Olenius, T., Onnela, A., Petäjä, T., Riccobono, F., Riipinen, I., Rissanen, M., Rondo, L., Ruuskanen, T., Santos, F. D., Sarnela, N., Schallhart, S., Schnitzhofer, R., Seinfeld J. H., Simon, M., Sipilä, M., Stozhkov, Y., Stratmann, F., Tomé, A., Tröst, J., Tsagkogeorgas, G., Vaattovaara, P., Viisanen, Y., Virtanen, A., Vrtala, A., Wagner, P. E., Weingartner, E., Wex, H., Williamson, C., Wimmer, D., Ye, P., Yli-Juuti, T., Carslaw, K. S., Kulmala, M., Curtius, J., Baltensperger, U., Worsnop, D. R., Vehkamäki, H., and Kirkby, J.: Molecular understanding of sulphuric acid-amine particle nucleation in the atmosphere, Nature, 502, 359-363, 2013.

Arnold, F., Curtius, J., Sierau, B., Bürger, V., Busen, R., and Schumann, U. : Detection of massive negative chemiions in the exhaust plume of a jet aircraft in flight, Geophys. Res. Lett., 26, 1577-1580, 1999.

Arnold, F., Pirjola, L., Aufmhoff, H., Schuck, T., Lähde, T., and Hämeri, K.: First gaseous sulfuric acid measurements in automobile exhaust: Implications for volatile nanoparticle formation. Atmos. Environ., 40, 7097-7105, 2006.

Arnold, F., Pirjola, L., Rönkkö, T., Reichl, U., Schlager, H., Lähde, T., Heikkilä, J., and Keskinen, J.: First on-line measurements of sulphuric acid gas in modern heavy duty diesel engine exhaust: Implications for nanoparticle formation, Environ. Sci. Technol., 46, 11227-11234, 2012.

Bilde, M., Svenningsson, B., Mønster, J., and Rosenørn, T.: Evenodd alternation of evaporation rates and vapor pressures of C3C9 dicarboxylic acid aerosols, Environ. Sci. Technol., 37, 13711378, 2003. 
Bond, T. C., Doherty, S. J., Fahey, D. W., Forster, P. M., Berntsen, T., DeAngelo, B. J., Flanner, M. G., Ghan, S., Kärcher, B., Koch, D., Kinne, S., Kondeo, Y., Quinn, P. K., Sarofim, M. C., Schultz, M. G., Schulz, M., Venkataraman, C., Zhang, H., Zhang, S., Bellouin, N., Guttikunda, K., Hopke, P. K., Jacobson, M. Z., Kaiser, J. W., Klimont, Z., Lohmann, U., Schwarz, J. P., Shindell, D., Storelvmo, T., Warren, S. G., and Zender, C. S.: Bounding the role of black carbon in the climate system: A scientific assessment, J. Geophys. Res.-Atmos., 118, 5380-5552, doi:10.1002/jgrd.50171, 2013.

Charlson, R. J., Schwartz, S. E., Hales, J. M., Cess, R. D., Coakley, J. A., Hansen, J. E., and Hofmann, D. J.: Climate forcing by anthropogenic aerosols, Science, 255, 423-430, 1992.

Clement, C. F. and Ford, I. J.: Gas-to-particle conversion in the atmosphere: II. Analytical models of nucleation bursts, Atmos. Environ., 33, 489-499, 1999.

Dal Maso, M., Liao, L., Wildt, J., Kiendler-Scharr, A., Kleist, E., Tillmann, R., Sipilä, M., Hakala, J., Lehtipalo, K., Ehn, M., Kerminen, V.-M., Kulmala, M., Worsnop, D., and Mentel, T.: A chamber study of the influence of boreal BVOC emissions and sulphuric acid on nanoparticle formation rates at ambient concentrations, Atmos. Chem. Phys. Discuss., 14, 31319-31360, doi:10.5194/acpd-14-31319-2014, 2014.

$\mathrm{Du}, \mathrm{H}$. and $\mathrm{Yu}, \mathrm{F}$.: Role of the binary $\mathrm{H}_{2} \mathrm{SO}_{4}-\mathrm{H}_{2} \mathrm{O}$ homogeneous nucleation in the formation of volatile nanoparticles in the vehicular exhaust, Atmos. Environ., 40, 7579-7588, 2006.

Du, H. and Yu, F.: Nanoparticle formation in the exhaust of vehicles running on ultra-low sulfur fuel, Atmos. Chem. Phys., 8, 47294739, doi:10.5194/acp-8-4729-2008, 2008.

Fiedler, V., Dal Maso, M., Boy, M., Aufmhoff, H., Hoffmann, J., Schuck, T., Birmili, W., Hanke, M., Uecker, J., Arnold, F., and Kulmala, M.: The contribution of sulphuric acid to atmospheric particle formation and growth: a comparison between boundary layers in Northern and Central Europe, Atmos. Chem. Phys., 5, 1773-1785, doi:10.5194/acp-5-1773-2005, 2005.

Filippo, A. and Maricq, M.: Diesel nucleation mode particles: Semivolatile or solid? Environ. Sci. Technol., 42, 7957-7962, 2008.

Fuchs, N. A.: The mechanics of aerosols, translated by: Daisley, R. E. and Fuchs, M., Dover Publications, New York, 1964.

Fuchs, N. A. and Sutugin, A. G.: High dispersed aerosols, in: Topics in current aerosol research (Part 2), edited by: Hidy, G. M. and Brock, J. R., Pergamon, New York, 1971.

FORTRAN-routine D02EAF: The NAG Workstation Library Handbook 1. The Numerical Algorithms Group Ltd., Oxford, 1990.

Giechaskiel, B., Ntziachristos, L., Samaras, Z., Scheer, V., Casati, R., and Vogt, R.: Formation potential of vehicle exhaust nucleation mode particles on-road and in the laboratory, Atmos. Environ. 39, 3191-3198, 2005.

Giechaskiel, B., Ntziachristo, L., and Samaras, Z.: Effect of ejector dilutors on measurements of automotive exhaust gas aerosol size distributions, Meas. Sci. Technol. 20, 45703-45710, 2009.

Hämeri, K., Charlson, R., and Hansson, H.-C., Hygroscopic properties of mixed ammonium sulfate and carboxylic acid particles, AIChE Journal, 48, 1309-1316, 2002.

Heikkilä, J., Rönkkö, T., Lähde, T., Lemmetty, M., Arffman, A., Virtanen, A., Keskinen, J., Pirjola, L., and Rothe, D.: Effect of open channel filter on particle emissions of modern diesel engine, J. Air Waste Manage. Assoc., 59, 1148-1154, 2009.
Hussein, T., Dal Maso, M., Petäjä, T., Koponen, I. K., Paatero, P., Aalto, P. P., Hämeri, K., and Kulmala, M.: Evaluation of an automatic algorithm for fitting the particle number size distributions, Boreal Environ. Res., 10, 337-355, 2005.

Jacobson, M. Z.: Numerical techniques to solve condensational and dissolutional growth equations when growth is coupled to reversible reactions, Aerosol Sci. Technol., 27, 491-498, 1997.

Karjalainen, P., Pirjola, L., Heikkilä, J., Lähde, T., Tzamkiozis, T., Ntziachristos, L., Keskinen, J., and Rönkkö, T.: Exhaust particles of modern gasoline vehicles: laboratory and on-road study, Atmos. Environ., 97, 262-270, 2014.

Karl, M., Gross, A., Pirjola, L., and Leck, C.: A new flexible multicomponent model for the study of aerosol dynamics in the marine boundary layer, Tellus B, 63, 1001-1025, doi:10.1111/j.16000889.2011.00562.x, 2011.

Karl, M., Leck, C., Gross, A., and Pirjola, L.: A study of new particle formation in the marine boundary layer over the central Arctic Ocean using a flexible multicomponent aerosol dynamic model, Tellus B, 64, 17158, doi:10.3402/tellusb.v64i0.17158, 2012a.

Karl, M., Dye, C., Schmidbauer, N., Wisthaler, A., Mikoviny, T., D’Anna, B., Müller, M., Borrás, E., Clemente, E., Muñoz, A., Porras, R., Ródenas, M., Vázquez, M., and Brauers, T.: Study of OH-initiated degradation of 2-aminoethanol, Atmos. Chem. Phys., 12, 1881-1901, doi:10.5194/acp-12-1881-2012, 2012 b.

Kawamura, K. and Kaplan, I. R.: Motor exhaust emissions as a primary source for dicarboxylic acid in Los Angeles ambient air, Environ. Sci. Technol., 21, 105-110, 1987.

Keskinen, J. and Rönkkö, T.: Can Real-World Diesel Exhaust Particle Size Distribution be Reproduced in the Laboratory? A Critical Review, J. Air Waste Manage. Assoc., 60, 1245-1255, 2010.

Keskinen, J., Pietarinen, K., and Lehtimäki, M.: Electrical low pressure impactor, J. Aerosol Sci., 23, 353-360, 1992.

Kettunen, J., Lanki, T., Tiittanen, P., Aalto, P. P., Koskentalo, T., Kulmala, M., Salomaa, V., and Pekkanen, J.: Associations of fine and ultrafine particulate air pollution with stroke mortality in an area of low air pollution levels, Stroke, 38, 918-922, 2007.

Keuken, M. P., Henzing, J. S., Zandveld, P., van den Elshout, S., and Karl, M.: Dispersion of particle numbers and elemental carbon from road- traffic, a harbor and an airstrip in the Netherlands, Atmos. Environ., 54, 320-327, 2012.

Khalek, I. A., Spears, M., and Charmley, W.: Particle size distribution from heady-duty diesel engine: Steady-state and transient emission measurement using two dilution systems and two fuels, SAE Technical Paper Series, 2003-01-0285, 2003.

Kittelson, D. B.: Engines and nanoparticles: A review, J. Aerosol Sci., 29, 575-588, 1998.

Kittelson, D. B., Kadue, P. A., Scherrer, H. C., and Loverien, R. E.: Characterization of diesel particle in the atmosphere, CRC, AP-2 Project Group, 1988.

Kittelson, D. B., Watts, W. F., Johnson, J. P., Thorne, C., Higham, C., Payne, J., Goodier, S., Warrens, C., Preston, H., Zink, U., Pickles, D., Goersmann, C., Twigg, M. V., Walker, A. P., and Boddy, R.: Effect of fuel and lube oil sulfur on the performance of a diesel exhaust gas continuously regenerating trap, Environ. Sci. Technol., 42, 9276-9282, 2008.

Kulmala, M., Laaksonen, A., and Pirjola, L.: Parameterizations for sulfuric acid/water nucleation rates, J. Geophys. Res., 103, 83018308, 1998. 
Kulmala, M., Dal Maso, M., Mäkelä, J. M., Pirjola, L., Väkevä, M., Aalto, P., Miikkulainen, P., Hämeri, K., and O'Dowd, C. D.: On the formation, growth and composition of nucleation mode particles, Tellus, 53B, 479-490, 2001.

Kulmala, M., Lehtinen, K. E. J., and Laaksonen, A.: Cluster activation theory as an explanation of the linear dependence between formation rate of $3 \mathrm{~nm}$ particles and sulphuric acid concentration, Atmos. Chem. Phys., 6, 787-793, doi:10.5194/acp-6-787-2006, 2006.

Kulmala, M., Riipinen, I., Sipilä, M., Manninen, H. E., Petäjä, T., Junninen, H., Dal Maso, M., Mordas, G., Mirme, A., Vana, M., Hirsikko, A., Laakso, L., Harrison, R. M., Hanson, I., Leung, C., Lehtinen, K. E. J., Kerminen, V.-M., and Kulmala, M.: Toward direct measurement of atmospheric nucleation, Science, 318, 8992, 2007.

Kuuluvainen, H., Saukko, E., Karjalainen, P., Nousiainen, P., Karhu, T., Pirjola, L., Keskinen, J., and Rönkkö, T.: Diesel engine exhaust particle measurements using a particle size magnifier (PSM), Abstracts of the European Aerosol Conference 2015, Milan, Italy, 6-11 September, 37COA-O017, 2015.

Lähde, T., Rönkkö, T., Virtanen, A., Solla, A., Kytö, M., Söderström, C., and Keskinen, J.: Dependence between non-volatile nucleation mode particle and soot number concentrations in an EGR equipped heavy duty diesel engine exhaust, Environ. Sci. Technol., 44, 3175-3180, 2010.

Lehtinen, K. E. J. and Kulmala, M.: A model for particle formation and growth in the atmosphere with molecular resolution in size, Atmos. Chem. Phys., 3, 251-257, doi:10.5194/acp-3-251-2003, 2003

Lemmon, E. W. and Goodwin, A. R. H.: Critical properties and vapor pressure equation for alkanes $\mathrm{C}_{n} \mathrm{H}_{2 n+2}$ : normal alkanes and isomers for $\mathrm{n}=4$ through $\mathrm{n}=9$. J. Phys. Chem. Ref. Data, 29, 139, 2000.

Lemmetty, M., Pirjola, L., Mäkelä, J. M., Rönkkö, T., and Keskinen, J.: Computation of maximum rate of water-sulphuric acid nucleation in diesel exhaust, J. Aerosol Sci., 37, 1596-1604, 2006.

Lemmetty, M., Rönkkö, T., Virtanen, A., Keskinen, J., and Pirjola, L.: The effect of sulphur in diesel exhaust aerosol: Models comparison with measurements, Aerosol Sci. Techno., 42, 916-929, doi:10.1080/02786820802360682, 2008.

Liu, Y. H., He, Z., and Chan, T. L.: Three-dimensional simulation of exhaust particle dispersion and concentration fields in the nearwake region of the studied ground vehicle, Aerosol Sci. Technol., 45, 1019-1030, doi:10.1080/02786826.2011.580021, 2011

Ma, H., Jung, H., and Kittelson, D. B.: Investigation of diesel nanoparticle nucleation mechanism, Aerosol Sci. Technol., 42, 335-342, 2008

Maricq, M., Chase, R., Xu, N., and Laing, P.: The effects of the catalytic converter and fuel sulphur level on motor vehicle particulate matter emissions: Light duty diesel vehicles, Environ. Sci. Technol., 36, 283-289, 2002.

Mathis, U., Ristimäki, J., Mohr, M., Keskinen, J., Ntziachristos, L., Samaras, Z., and Mikkanen, P.: Sampling conditions for the measurement of nucleation mode particles in the exhaust of a diesel vehicle, Aerosol Sci. Technol., 38, 1149-1160, 2004.

McMurry, P. H. and Friedlander, S. K.: New particle formation in the presence of an aerosol, Atmos. Environ., 13, 1635-1651, 1979.
Merikanto, J., Napari, I., Vehkamäki, H., Anttila, T., and Kulmala, M.: New parameterization of sulfuric acid-ammonia-water ternary nucleation rates at tropospheric conditions, J. Geophys. Res., 112, D15207, doi:10.1029/2006JD007977, 2002.

Napari, I., Noppel, M., Vehkamäki, H., and Kulmala, M.: Parameterization of ternary nucleation rates for $\mathrm{H}_{2} \mathrm{SO}_{4}-\mathrm{NH}_{3}-\mathrm{H}_{2} \mathrm{O}$ vapors, J. Geophys. Res., 107, 4381, doi:10.1029/2002JD002131, 2007.

Ntziachristos, L., Giechaskiel, B., Pistikopoulos, P., Samaras, Z., Mathis, U., Mohr, M., Ristimäki, J., Keskinen, J., Mikkanen, P., Casati, R., and Scheer, V., Vogt, R.: Performance evaluation of a novel sampling and measurement system for exhaust particle characterization, SAE Technical Paper Series 2004-01-1439, 2004.

Olin, M., Rönkkö, T., and Dal Maso, M.: CFD modeling of a vehicle exhaust laboratory sampling system: sulfur-driven nucleation and growth in diluting diesel exhaust, Atmos. Chem. Phys., 15, 5305-5323, doi:10.5194/acp-15-5305-2015, 2015.

Paasonen, P., Nieminen, T., Asmi, E., Manninen, H. E., Petäjä, T., Plass-Dülmer, C., Flentje, H., Birmili, W., Wiedensohler, A., Hõrrak, U., Metzger, A., Hamed, A., Laaksonen, A., Facchini, M. C., Kerminen, V.-M., and Kulmala, M.: On the roles of sulphuric acid and low-volatility organic vapours in the initial steps of atmospheric new particle formation, Atmos. Chem. Phys., 10, 11223-11242, doi:10.5194/acp-10-11223-2010, 2010.

Peng, C. and Chan, C. K.: The water cycles of water-soluble organic salts of atmospheric importance, Atmos. Environ., 35, 11831192, 2001.

Pey, J., Querol, X., Alastuey, A., Rodriguez, S., Putaud, J. P., and Van Dingenen, R.: Source apportionment of urban fine and ultrafine particle number concentration in a Western Mediterranean city, Atmos. Environ., 43, 4407-4415, 2009.

Pirjola, L.: Effects of the increased UV radiation and biogenic VOC emissions on ultrafine aerosol formation, J. Aerosol. Sci., 30, 355-367, 1999.

Pirjola, L. and Kulmala, M.: Development of particle size and composition distribution with a novel aerosol dynamics model, Tellus, 53B, 491-509, 2001.

Pirjola, L., Lehtinen, K. E. J., Hansson, H.-C., and Kulmala, M.: How important is nucleation in regional/global modelling, Geophys. Res. Lett., 31, L12109, doi:10.1029/2004GL019525, 2004.

Pope III, C. A. and Dockery, D. W.: Health effects of fine particulate air pollution: lines that connect, J. Air Waste Manage. Assoc., 56, 707-742, 2006.

Pyykönen, J., Miettinen, M., Sippula, O., Leskinen, A., Raunemaa, T., and Jokiniemi, J.: Nucleation in a perforated tube diluter, J. Aerosol Sci., 38, 172-191, 2007.

Raes, F. and Janssens, A.: Ion-induced aerosol formation in a $\mathrm{H}_{2} \mathrm{O}$ $\mathrm{H}_{2} \mathrm{SO}_{4}$ system. 1. Extension of the classical theory and search for experimental evidence, J. Aerosol Sci., 16, 217-227, 1985.

Riccobono, F., Almeida, J., Schobesberger, S., Scott, C. E., Dommen, J., Ortega, I. K., Rondo, L., Almeida, J., Amorim, A., Bianchi, F., Breitenlechner, M., David, A., Downard, A., Dunne, E. M., Duplissy, J., Ehrhart, S., Flagan, R. C., Franchin, A., Hansel, A., Junninen, H., Kajos, M., Keskinen, H., Kupc, A., Kürten, A., Kvashin, A. N., Laaksonen, A., Lehtipalo, K., Makhmutov, V., Mathot, S., Nieminen, T., Onnela, A., Petäjä, T., Praplan, A. P., Santos, F. D., Schallhart, S., Seinfeld, J. H., Sipilä, M., Spracklen, D. V., Stozhkov, Y., Stratmann, F., Tomé, 
A., Tsagkogeorgas, G., Vaattovaara, P., Viisanen, Y., Vrtala, A., Wagner, P. E., Weingartner, E., Wex, H., Wimmer, D., Carslaw, K. S., Curtius, J., Donahue, N. M., Kirkby, J., Kulmala, M., Worsnop, D. R., and Baltensperger, U.: Oxidation Products of Biogenic Emissions Contribute to Nucleation of Atmospheric Particle, Science, 344, 717-721, 2014.

Riipinen, I., Koponen, I. K., Frank, G. P., Hyvärinen, A.-P., Vanhanen, J., Lihavainen, H. L., Lehtinen, K. E. J., Bilde, M., and Kulmala, M.: Adipic and Malonic Acid Aqueous Solutions: Surface Tensions and Saturation Vapor Pressures, J. Phys. Chem. A, 111, 12995-13002, 2007.

Robinson, A. L, Donahue, N. M., Shrivastava, M. K., Weitkamp, E. A., Sage, A. M., Grieshop, A. P., Lane, T. E., Pierce, J. R., and Pandis, S. N.: Rethinking organic aerosols: Semivolatile emissions and photochemical aging, Science, 315, 1259-1262, 2007.

Rönkkö, T., Virtanen, A., Vaaraslahti, K., Keskinen, J., Pirjola, L., and Lappi, M.: Effect of dilution conditions and driving parameters on nucleation mode particles in diesel exhaust: laboratory and on-road study, Atmos. Environ., 40, 2893-2901, 2006.

Rönkkö, T., Virtanen, A., Kannosto, J., Keskinen, J., Lappi, M., and Pirjola, L.: Nucleation mode particles with a non-volatile core in the exhaust of a heavy duty diesel vehicle. Environ. Sci. Technol., 41, 6384-6389, doi:10.1021/es0705339, 2007.

Rönkkö, T., Lähde, T., Heikkilä, J., Pirjola, L., Bauschke, U., Arnold, F., Schlager, H., Rothe, D., Yli-Ojanperä, J., and Keskinen, J.: Effect of gaseous sulphuric acid on diesel exhaust nanoparticle formation and characteristics, Environ. Sci. Technol., 47, 11882-11889, doi:10.1021/es402354y, 2013.

Sakurai, H., Park, K., McMurry, P. H., Zarling, D. D., Kittelson, D. B., and Ziemann, P. J.: Size-dependent mixing characteristics of volatile and nonvolatile components in diesel exhaust aerosols, Environ. Sci. Technol., 37, 5487-5495, 2003.

Schneider, J., Hock, N., Weimer, S., Borrmann, S., Kirchner, U., Vogt, R., and Scheer, V.: Nucleation particles in diesel exhaust: Composition inferred from in situ mass spectrometer analysis, Environ. Sci. Technol., 39, 6153-6161, 2005.

Shi, J. and Harrison, R.: Investigation of ultrafine particle formation during diesel exhaust dilution, Environ. Sci. Technol., 33, 37303736, 1999.

Sihto, S.-L., Kulmala, M., Kerminen, V.-M., Dal Maso, M., Petäjä, T., Riipinen, I., Korhonen, H., Arnold, F., Janson, R., Boy, M., Laaksonen, A., and Lehtinen, K. E. J.: Atmospheric sulphuric acid and aerosol formation: implications from atmospheric measurements for nucleation and early growth mechanisms, Atmos. Chem. Phys., 6, 4079-4091, doi:10.5194/acp-6-4079-2006, 2006.

Sioutas, C., Delfino, R. J., and Singh, M.: Exposure assessment for atmospheric ultrafine particles (UFPs) and implications in epidemiologic research, Environ. Health Perspect., 113, 947-955, 2005.

Sipilä, M., Berndt, T., Petäjä, T., Brus, D., Vanhanen, J., Stratmann, F., Patokoski, J., Mauldin III, R. L., Hyvärinen, A.-P., Lihavainen, H., and Kulmala, M.: The role of sulfuric acid in atmospheric nucleation, Science, 327, 1243-1246, 2010.
Su, D. S., Serafino, A., Müller, J-O., Jentoft, R. E., Schlögl, R., and Fiorito, S.: Cytotoxicity and Inflammatory Potential of Soot Particles of Low-Emission Diesel Engines, Environ. Sci. Technol., 42, 1761-1765, 2008.

Tobias, H., Beving, D., Ziemann, P., Sakurai, H., Zuk, M., McMurry, P., Zarling, D., Watylonis, R., and Kittelson, D.: Chemical analysis of diesel engine nanoparticles using a nanoDMA/thermal desorption particle beam mass spectrometer, Environ. Sci. Technol., 35, 2233-2243, 2001.

Uhrner, U., von Löwis, S., Vehkamäki, H., Wehner, B., Bräsel, S., Hermann, M., Stratmann, F., Kulmala, J., and Wiedensohler, A.: Dilution and aerosol dynamics within a diesel car exhaust plume - CFD simulations of on-road measurement conditions, Atmos. Environ., 41, 7440-7461, 2007.

Vaaraslahti, K., Keskinen, J., Giechaskiel, B., Solla, A., Murtonen, T., and Vesala, H.: Effect of lubricant on the formation of heavyduty diesel exhaust particles, Environ. Sci. Technol., 39, 84978504, 2005.

Vehkamäki, H., Kulmala, M., Napari, I., Lehtinen, K. E. J., Timmreck, C., Noppel, M., and Laaksonen, A.: An improved parameterization for sulphuric acid-water nucleation rates for tropospheric and stratospheric conditions, J. Geophys. Res., 107, 4622, doi:10.1029/2002JD002184, 2002.

Vehkamäki, H., Kulmala, M., Lehtinen, K. E. J., and Noppel, M.: Modelling binary homogeneous nucleation of water-sulfuric acid vapours: parameterisation for high temperature emissions, Environ. Sci. Technol., 37, 3392-3398, 2003.

Virtanen, A., Ristimäki, J., Marjamäki, M., Vaaraslahti, K., Keskinen, J., and Lappi, M.: Effective Density of Diesel Exhaust Particles as a Function of Size, SAE Tech. Pap. Ser. 2002-01-0056, 2002.

Vouitsis, E., Ntziachristos, L., and Samaras, Z.: Modelling of diesel exhaust aerosol during laboratory sampling, Atmos. Environ., 39, 1335-1345, 2005.

Wang, Y. J. and Zhang, W. K. M.: Coupled turbulence and aerosol dynamics modelling of vehicle exhaust plumes using the CTAG model, Atmos. Environ., 59, 284-293, 2012.

Weber, R. J., Marti, J. J., McMurry, P. H., Eisele, F. L., Tanner, D. J., and Jefferson, A.: Measurements of new particle formation and ultrafine particle growth rates at a clean continental site, J. Geophys. Res., 102, 4375-4385, 1997.

Yeung, M. C., Lee, A. K. Y., and Chan, C. K.: Phase transition and hygroscopic properties of internally mixed ammonium sulfate and adipic Acid (AS-AA) particles by optical microscopic imaging and Raman spectroscopy, Aerosol Sci. Technol., 43, 387399, 2009.

Yu, F. and Turco, R. P.: Ultrafine aerosol formation vie ion-mediated nucleation, Geophys. Res. Lett., 6, 883-886, 2000.

Zervas, E., Montagne, X., and Lahaye, J.: C1-C5 organic acid emissions from an SI engine: Influence of fuel and air/fuel equivalence ratio. Environ. Sci. Technol., 35, 2746-2751, 2001. 